\title{
Smaller Footprint Drilling System for Deep and Hard Rock Environments; Feasibility of Ultra-High Speed Diamond Drilling
}

Topical Report

Reporting Period Start Date - June 23, 2003

Reporting Period End Date - September 30, 2004

Authors; $\quad$ Alan Black, TerraTek Arnis Judzis, TerraTek

Report Date - October, 2004

DOE Award Number - DE-FC26-03NT15401

TerraTek, Inc. 400 Wakara Way

Salt Lake City, UT 84108 


\section{DISCLAIMER}

This report was prepared an as account of work sponsored by an agency of the United States Government. Neither the United States Government nor any agency thereof, nor any of their employees, makes any warranty, express or implied, or assumes any legal liability or responsibility for the accuracy, completeness, or usefulness of any information, apparatus, product, or process disclosed, or represents that its use would not infringe privately owned rights. Reference herein to any specific commercial product, process, or service by trade name, trademark, manufacturer, or otherwise does not necessarily constitute or imply its endorsement, recommendation, or favoring by the United States Government or any agency thereof. The views and opinions of authors expressed herein do not necessarily state or reflect those of the United States Government or any agency thereof. 


\section{ABSTRACT}

The two phase program addresses long-term developments in deep well and hard rock drilling. TerraTek believes that significant improvements in drilling deep hard rock will be obtained by applying ultra-high (greater than 10,000 rpm) rotational speeds. The work includes a feasibility of concept research effort aimed at development and test results that will ultimately result in the ability to reliably drill 'faster and deeper' possibly with rigs having a smaller footprint to be more mobile. The principle focus is on demonstration testing of diamond bits rotating at speeds in excess of 10,000 rpm to achieve high rate of penetration rock cutting with substantially lower inputs of energy and loads.

The project draws on TerraTek results submitted to NASA's 'Drilling on Mars' program. The objective of that program was to demonstrate miniaturization of a robust and mobile drilling system that expends small amounts of energy. TerraTek successfully tested ultrahigh speed $(\sim 40,000 \mathrm{rpm})$ small kerf diamond coring. Adaptation to the oilfield will require innovative bit designs for full hole drilling or continuous coring and the eventual development of downhole ultra-high speed drives.

For domestic operations involving hard rock and deep oil and gas plays, improvements in penetration rates is an opportunity to reduce well costs and make viable certain field developments. An estimate of North American hard rock drilling costs is in excess of $\$ 1,200$ MM. Thus potential savings of $\$ 200 \mathrm{MM}$ to $\$ 600 \mathrm{MM}$ are possible if drilling rates are doubled [assuming bit life is reasonable]. The net result for operators is improved profit margin as well as an improved position on reserves.

The significance of the 'ultra-high rotary speed drilling system' is the ability to drill into rock at very low weights on bit and possibly lower energy levels. The drilling and coring industry today does not practice this technology. The highest rotary speed systems in oil field and mining drilling and coring today run less than 10,000 rpm—usually well below $5,000 \mathrm{rpm}$.

This document details the progress to date on the program entitled SMALLER FOOTPRINT DRILLING SYSTEM FOR DEEP AND HARD ROCK ENVIRONMENTS; FEASIBILITY OF ULTRA-HIGH SPEED DIAMOND DRILLING for the period starting June 23, 2003 through September 30, 2004.

- TerraTek has reviewed applicable literature and documentation and has convened a project kick-off meeting with Industry Advisors in attendance.

- TerraTek has designed and planned Phase I bench scale experiments. Some difficulties in obtaining ultra-high speed motors for this feasibility work were encountered though they were sourced mid 2004.

- TerraTek is progressing through Task 3 "Small-scale cutting performance tests". Some improvements over early NASA experiments have been identified. 


\section{TABLE OF CONTENTS}

Title Page $\ldots \ldots \ldots \ldots \ldots \ldots \ldots \ldots \ldots \ldots \ldots \ldots \ldots \ldots \ldots \ldots \ldots \ldots \ldots \ldots \ldots, 1$

Disclaimer .......................................................... 2

Abstract .............................................................. 3

Table of Contents ................................................. 4

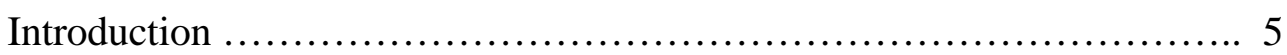

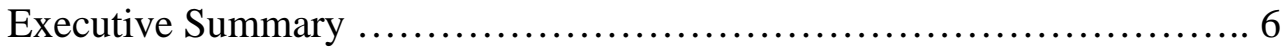

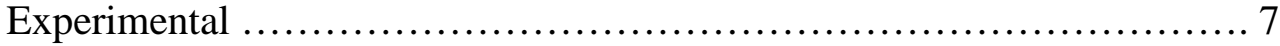

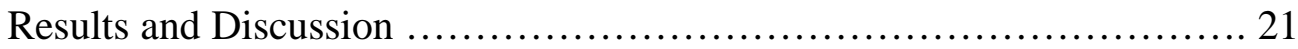

Conclusions ..................................................... 27 


\section{INTRODUCTION}

The focus for the Introduction will be the assessment of harder rock drilling environments requiring novel technologies and tools (Task 1) and a view of the equipment being utilized for Phase 1 of the study.

The review of industry practices has shown that in general, rotary speeds above 1000 RPM have not been utilized in the drilling of oil and gas wells. Rotary speeds above 1000 to 50,000 plus RPM have been used successfully to machine or remove hard materials such as ceramics, enamels, and the like. These materials are removed quite efficiently using high RPM and small thrust loads. The most common application is dental work where diamond grit tools are rotated up to 30,000 RPM while being driven by air turbines and cooled by additional mist systems. Mining applications regularly use rotary speeds up to 2,000 RPM coupled to either surface set natural diamond bits or impregnated bits to drill economically.

There have been a few excursions into the higher than normal "mud turbine" rotary speeds, but the concept of driving the bits at high and ultra high RPM has not materialized. An air turbine for downhole applications was operated up to 40,000 RPM but had a gear reduction box coupled to the turbine, which dropped the bit rotary speed back to normal mud motor or rotary drilling range (200 RPM).

The general practice for drilling oil and gas wells uses rotary speeds up to about 150 RPM, mud motors with rotary speeds up to about 400 RPM operating at a preference towards speeds of 200 to 250 RPM, and mud turbine drilling turning bits at a maximum RPM of about 1000. Although it appears that the direction to move in removing harder materials, including rock, might lie in high and ultra high rotary speed systems. There does not appear to be any current or past history that shows a technology direction towards tools or systems that incorporate high or ultra high rotary speed, except for dental or machining industries.

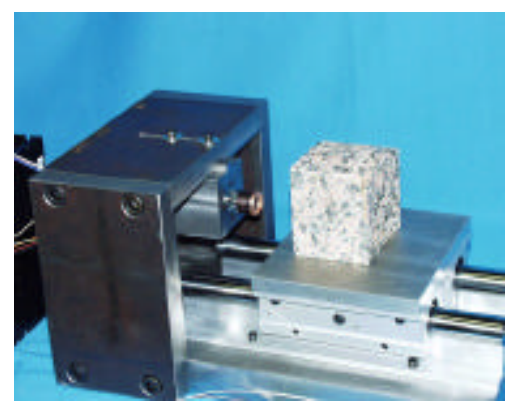




\section{EXECUTIVE SUMMARY}

\section{$\underline{\text { Background }}$}

On August 26, 2003, details of the Feasibility of Ultra-High Speed Diamond Drilling Project were presented at a 'kick-off' meeting held at NPTO's offices in Tulsa, Oklahoma. Industry Advisors from Shell Exploration and Production as well as ReedHycalog attended.

- TerraTek has reviewed applicable literature and documentation and has convened a project kick-off meeting with Industry Advisors in attendance.

- TerraTek has designed and planned Phase I bench scale experiments. Some difficulties in obtaining ultra-high speed motors for this feasibility work were encountered though they were sourced mid 2004.

- TerraTek is progressing through Task 3 "Small-scale cutting performance tests". Some improvements over early NASA experiments have been identified.

\section{$\underline{\text { Current }}$}

TerraTek is proceeding with Task 3 experiments even though delays have been encountered. 


\section{EXPERIMENTAL}

\section{$\underline{\text { Sept-December } 2003}$}

Modified ultra-high speed equipment to accommodate water flow, prepared Berea sandstone, Indiana limestone and Colton sandstone rock samples and prepared some of the blocks with holes and glued in fittings for supplying water to the center of the bits. During this period, the Specific Energy calculations were examined and it was determined that the Specific Energy calculations used in the Mars project had been divided by $2 * \mathrm{Pi}$ or 6.2832 by mistake. A calibration error was also found for one data point in the Mars project (Berea, $3 \mathrm{Kgm} \mathrm{WOB}$ data) which changed the shape of the curve to be more in line with what might be expected (lower Specific Energy at higher rotational speeds). The Mars project data presented in this report has been corrected. Also, it was decided to report Specific Energy mainly in units of $\mathrm{ft}-\mathrm{lbs} / \mathrm{cu}$. in. but also shown in Joules/cu. meter units. Confirmation of the correctness of our current Specific Energy calculations was made by Marcel Boucher at Reed-Hycalog and David Curry at Hughes Christensen.

$\underline{\text { January } 2004}$

Ran several checkout tests with an existing bit used extensively in the Mars project. The intent was to run a series of tests in Berea sandstone and Indiana limestone with nitrogen and water. After starting the testing with nitrogen in Berea sandstone, it was found that the penetration rates achieved in the Mars project could not be duplicated. Penetration rates were $20-60 \mathrm{ft} / \mathrm{hr}$ at 5000 to $42000 \mathrm{rpm}$ compared with $110-170 \mathrm{ft} / \mathrm{hr}$ at 27000 to $42000 \mathrm{rpm}$ in the Mars project for $3 \mathrm{Kgm}$ WOB. Two things were discovered: 1) the diamonds on the Mars bit had significant wear flats and 2) the ultra-high speed motor bearings were worn. It was decided not to test further until new bits and motors could be obtained.

$\underline{\text { January-May } 2004}$

Five new bits were fabricated and balanced and three new ultra-high speed motors were obtained. The bit bodies (0.704" OD x 0.624 " ID x 0.75 " drilling length) were machined at TerraTek and the diamonds attached by Scorpion Engineering of West Jordan, Utah using an electrolis attachment process (same as the Mars project bit) and they had a diamond size of 30 to 40 mesh. With the diamonds attached, the OD and ID were nominally 0.775 " and 0.565 ", respectively. The bits were balanced at speed between 2000 and 5000 rpm by Rotary Equipment Specialties of Elmhurst, Illinois. The motors were supplied to the project by Korford Engineering of DePlains, Illinois. The motor description includes: 42BD300H Mod 1.6" Halls Effect, 52,000 rpm motor with hollow shaft (0.249" OD x 0.125 " ID). While waiting for the bits and motors, an additional checkout test was run with the worn motor and the Mars bit with water to check out the methods developed to keep the motor dry. The concept tested was to blow nitrogen 
through the bit (through the motor shaft) at the same time the water was introduced through a hole in the rock into the center of the bit. It was felt that the nitrogen flow would keep water out of the motor, however, during the test, water entered into the used motor and it was ruined. It was determined from this failure that for future tests, the center of the bit needed to be plugged to prevent direct movement of the water into the motors hollow shaft.

June 2004

A test was run with a new motor and bit into Indiana limestone with nitrogen flow and the motor stalled and destroyed the new motor. It was determined after the failure that there had not been adequate nitrogen flow to clean the bit resulting in the stalled motor. Also in this time frame, Dennis Tool supplied TerraTek with a bit to be tested on the program. The bit has a saw tooth design. Due to efforts to resolve other issues on the project with the standard diamond bits, we have not attempted as yet to test the Dennis Tool bit.

$\underline{\text { July- August } 2004}$

No activity

September 2004

A new motor was installed and a series of preliminary tests were planned in Berea sandstone and Indiana limestone with nitrogen and water. Tests were first run at different nitrogen flows to determine its effect on bit cleaning and also the resulting pressure effect to reduce WOB. During these tests, ROP's of 12 to $87 \mathrm{ft} / \mathrm{hr}$ for speeds of 17000 to 40000 rpm were achieved, again much less than in the Mars project. The two bits used in these tests (Bit 1 and Bit 4) were relatively heavily set with diamonds compared with the Mars project bit and could explain the lower ROP. Also, Bit 4 experienced extreme vibrations and the hole enlargement at rotational speeds above $25000 \mathrm{rpm}$. A table of all the results to date includes the calculation of Specific Energy in ft-lbs/cu. in. and Joules/cu. meter. Plots of Specific Energy and versus Rotational Speed and ROP versus Rotational Speed comparing the results of the checkout tests with the worn, light set Mars project bit, the preliminary tests with the two new, heavily set bits and the new, light set Mars project bit drilling in Berea sandstone with nitrogen flow and $3 \mathrm{Kgm} \mathrm{WOB}$ is shown. It may be that the nitrogen flow rate is still to low to adequately clean the bits and needs to further investigated or that the heavily set new bits results in the lower ROP's and that WOB needs to be increased. The heavily set new bits will have more contact area with the formation being cut and also less flow area for the cuttings to be removed from. We also ran two test in Indiana limestone and only achieved about $1 \mathrm{ft} / \mathrm{hr}$ penetration rate. Again, this might be due to inadequate cleaning. We are considering dropping Indiana limestone as a test rock for now until more is learned about the reason for the very low ROP's and very high Specific Energies in Indiana limestone. In addition, all five of the new bits were mounted on a new motor and rotated from 0 to $50,000 \mathrm{rpm}$. All of the bits experience what is believed to be a resonant frequency starting between 34,000 to 38,000 
rpm. Three of the bits then smoothed out after passing through the resonant zone, but two showed ever increasing bit vibration beyond the on-set of resonant behavior. More effort is needed to get the bits correctly balanced. The next series of tests will be run with Bit 2, which seems to be the best balanced bit. The number of diamonds on Bit \#2 is 80 , compared with 55 on the 'Mars' bit used in the preliminary tests. In addition, Marcel Boucher at Reed-Hycalog offered to get several bits fabricated from Texas Diamond.

\section{Plans for October-November 2004}

Work on getting bits better balanced.

If the existing bits cannot be balanced properly, it may be necessary to fabricate new bits with more precise dimensions, with lighter set diamonds and shorter drilling stroke to reduce gravity effects on the longer bits.

Work on determining the optimum nitrogen flow rate to clean and cool bits.

Test stable bits in Berea sandstone and Colton sandstone with nitrogen and then water flow to establish baseline data for the project.

\begin{tabular}{|c|c|c|c|c|c|c|c|c|c|c|c|c|c|c|c|c|c|c|c|}
\hline \multicolumn{8}{|c|}{ Test Description (nominal values) } & \multicolumn{7}{|c|}{ Test Results } & \multicolumn{4}{|l|}{ Calculations } & \multirow[b]{3}{*}{ Comments } \\
\hline Test \# & Test & Bit & Rock & Fluid & woB & RPM & Travel & Hole OD & Hole ID & Volts & Amps & RPM & woB & ROP & S. E. Rotation & S. E. WOB & Total S. E. & Total S. E. & \\
\hline & Date & & & & $(\mathrm{kg})$ & (rpm) & (in) & (in) & (In) & (v) & (a) & (rpm) & (gms) & (in/sec) & (ft-lbs/in $\left.{ }^{3}\right)$ & $\left(\mathrm{ft}-\mathrm{lbs} / \mathrm{in}^{3}\right)$ & $\left(\mathrm{ft}-\mathrm{lbs} / \mathrm{in}^{3}\right)$ & $\left(\right.$ Joules $\left./ \mathrm{m}^{3}\right)$ & \\
\hline DOE1a & $1 / 12 / 04$ & Mars & Berea & Nitrogen & 3 & 10000 & 0.750 & 0.765 & 0.559 & 117.0 & 1.2575 & 5451.90 & 3000.0 & 0.08294 & 6112.93 & 2.58 & 6115.50 & $5.06 \mathrm{E}+08$ & \\
\hline DOE2a & $1 / 12 / 04$ & Mars & Berea & Nitrogen & 3 & 30000 & 0.750 & 0.783 & 0.547 & 116.8 & 2.2260 & 22927.05 & 3000.0 & 0.18057 & 4308.37 & 2.24 & 4310.60 & $3.56 \mathrm{E}+08$ & \\
\hline DOE2C & $1 / 14 / 04$ & Mars & Berea & Nitrogen & 3 & 40000 & 0.750 & 0.807 & 0.524 & 113.6 & 0.4097 & 41727.98 & 3000.0 & 0.07133 & 1626.87 & 1.86 & 1628.74 & $1.35 \mathrm{E}+08$ & Oversize Hole \\
\hline DOE3a & $1 / 14 / 04$ & Mars & Berea & Nitrogen & 3 & 20000 & 0.750 & 0.776 & 0.560 & 116.5 & 1.4350 & 14566.46 & 3000.0 & 0.09817 & 5542.47 & 2.43 & 5544.90 & $4.58 \mathrm{E}+08$ & \\
\hline DOE3b & $1 / 14 / 04$ & Mars & Berea & Nitrogen & 3 & 40000 & 0.750 & 0.775 & 0.558 & 115.8 & 2.0098 & 33889.61 & 3000.0 & 0.19085 & 3957.66 & 2.43 & 3960.08 & $3.27 \mathrm{E}+08$ & \\
\hline DOE3c & $1 / 14 / 04$ & Mars & Berea & Nitrogen & 3 & 43000 & 0.750 & 0.810 & 0.524 & 114.4 & 0.4408 & 41915.13 & 3000.0 & 0.04527 & 2741.97 & 1.84 & 2743.81 & $2.27 \mathrm{E}+08$ & Oversize Hole \\
\hline DOE3d & $1 / 14 / 04$ & Mars & Berea & Nitrogen & 3 & 15000 & 0.750 & 0.780 & 0.558 & 117.9 & 1.1744 & 11271.84 & 3000.0 & 0.07771 & 5630.98 & 2.36 & 5633.34 & $4.66 \mathrm{E}+08$ & \\
\hline DOE3e & $1 / 14 / 04$ & Mars & Berea & Nitrogen & 3 & 25000 & 0.750 & 0.778 & 0.563 & 117.2 & 1.5198 & 19864.48 & 3000.0 & 0.07837 & 7403.80 & 2.43 & 7406.23 & $6.12 \mathrm{E}+08$ & Motor Failing \\
\hline DOE3f & $1 / 14 / 04$ & Mars & Berea & Nitrogen & 3 & 35000 & 0.750 & 0.780 & 0.563 & 116.7 & 1.6843 & 29626.76 & 3000.0 & 0.07271 & 8708.53 & 2.41 & 8710.94 & $7.20 \mathrm{E}+08$ & Motor Failing \\
\hline Pre1 & 9/16/04 & 1 & Berea & $15 \mathrm{psin}$ & 2 & 25000 & 0.562 & 0.807 & 0.509 & 119.52 & 3.1842 & 17464.84 & 2000.0 & 0.289886 & 3144.04 & 1.19 & 3145.23 & $2.60 \mathrm{E}+08$ & Oversize Hole \\
\hline Pre2 & 9/16/04 & 1 & Berea & $50 \mathrm{psi} \mathrm{N}$ & 2 & 25000 & 0.552 & 0.802 & 0.516 & 120.00 & 2.1465 & 19628.43 & 2000.0 & 0.195500 & 3282.69 & 1.24 & 3283.94 & $2.71 \mathrm{E}+08$ & Oversize Hole \\
\hline Pre3 & $9 / 16 / 04$ & 1 & Berea & $100 \mathrm{psi} \mathrm{N}$ & 3 & 25000 & 0.590 & 0.799 & 0.522 & 120.40 & 2.3585 & 19363.35 & 3000.0 & 0.250731 & 2906.82 & 1.92 & 2908.74 & $2.40 \mathrm{E}+08$ & Oversize Hole \\
\hline Pre4 & $9 / 16 / 04$ & 4 & Berea & $100 \mathrm{psi} \mathrm{N}$ & 3 & 30000 & 0.577 & 0.769 & 0.544 & 121.52 & 0.3899 & 27849.78 & 2843.4 & 0.112922 & 1331.44 & 2.25 & 1333.69 & $1.10 \mathrm{E}+08$ & \\
\hline Pre5 & $9 / 16 / 04$ & 4 & Berea & $100 \mathrm{psi} \mathrm{N}$ & 3 & 40000 & 0.433 & 0.817 & 0.497 & 120.87 & 0.1497 & 39885.52 & 2842.1 & 0.041207 & 980.81 & 1.58 & 982.39 & $8.12 \mathrm{E}+07$ & Oversize Hole \\
\hline Pre6 & 9/16/04 & 4 & Berea & $100 \mathrm{psi} N$ & 3 & 50000 & 0.587 & 0.859 & 0.454 & 116.56 & 0.4690 & 43138.67 & 2842.7 & 0.311468 & 309.99 & 1.25 & 311.24 & $2.57 \mathrm{E}+07$ & Oversized, No Use \\
\hline Pre7 & $9 / 16 / 04$ & 4 & Ind & $100 \mathrm{psi} \mathrm{N}$ & 3 & 30000 & 0.357 & 0.755 & 0.560 & 121.95 & 0.5253 & 28911.64 & 2842.4 & 0.005739 & 40912.67 & 2.60 & 40915.26 & $3.38 \mathrm{E}+09$ & \\
\hline Pre8 & $9 / 16 / 04$ & 4 & Ind & $100 \mathrm{psi} \mathrm{N}$ & 3 & 40000 & 0.357 & 0.757 & 0.561 & 121.85 & 0.5380 & 28974.24 & 2839.9 & 0.004360 & 54823.02 & 2.58 & 54825.60 & 4.53E+09 & \\
\hline
\end{tabular}




\begin{tabular}{|c|c|c|c|c|c|c|c|c|}
\hline \multicolumn{2}{|l|}{ Berea, Mars Light Set Worn Bit, Nitrogen } & \multicolumn{2}{l|}{ Berea, New Heavy Set Bits 1 \& 4, Nitrogen } & \multicolumn{2}{c|}{ Berea, Mars New Light Set Bit, Nitrogen } \\
\hline RPM & Total S. E. & ROP (ft/hr) & RPM & Total S. E. & ROP (ft/hr) & RPM & Total S. E. & ROP (ft/hr) \\
\hline 5451.90 & 6115.50 & 24.88 & 17464.84 & 3145.23 & 86.97 & 26458.00 & 10033.02 & 152.70 \\
\hline 22927.05 & 4310.60 & 54.17 & 19628.43 & 3283.94 & 58.65 & 37793.00 & 6080.62 & 113.00 \\
\hline 41727.98 & 1628.74 & 21.40 & 19363.35 & 2908.74 & 75.22 & 41117.00 & 5624.57 & 167.90 \\
\hline 14566.46 & 5544.90 & 29.45 & 27849.78 & 1333.69 & 33.88 & & \\
\hline 33889.61 & 3960.08 & 57.26 & 39885.52 & 982.39 & 12.36 & & & \\
\hline 41915.13 & 2743.81 & 13.58 & & & & & & \\
\hline 11271.84 & 5633.34 & 23.31 & & & & & \\
\hline
\end{tabular}

Comparison of Data From DOE Checkout, DOE Prelim. and Mars Project with Berea Sandstone and Nitrogen

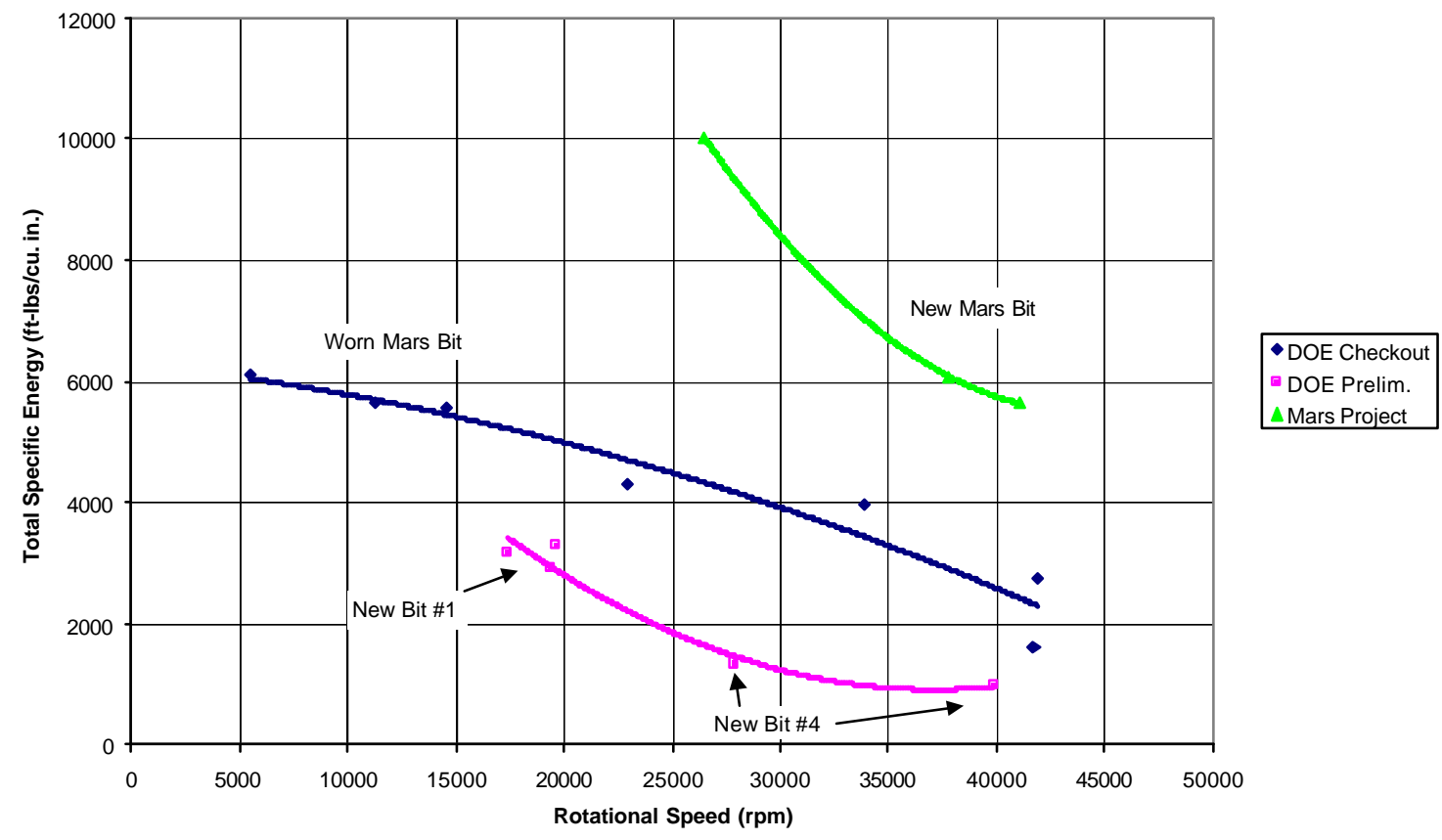




\section{Comparison of Data From DOE Checkout, DOE Prelim. and Mars Project with Berea Sandstone and Nitrogen}

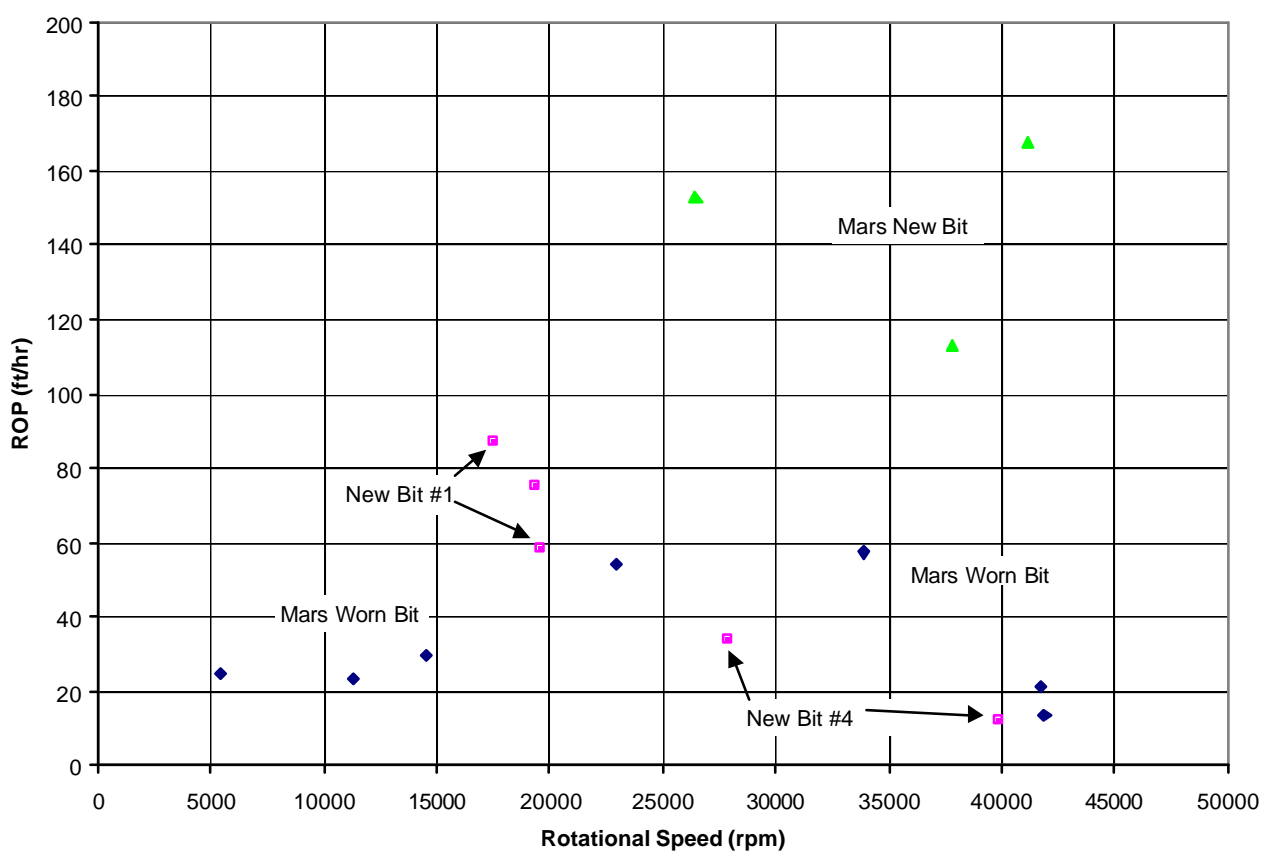

Early Check Out Test Results using Mars Worn Light Set Bit with Berea Sandstone at $3 \mathrm{Kgm}$ WOB and Nitrogen Flow

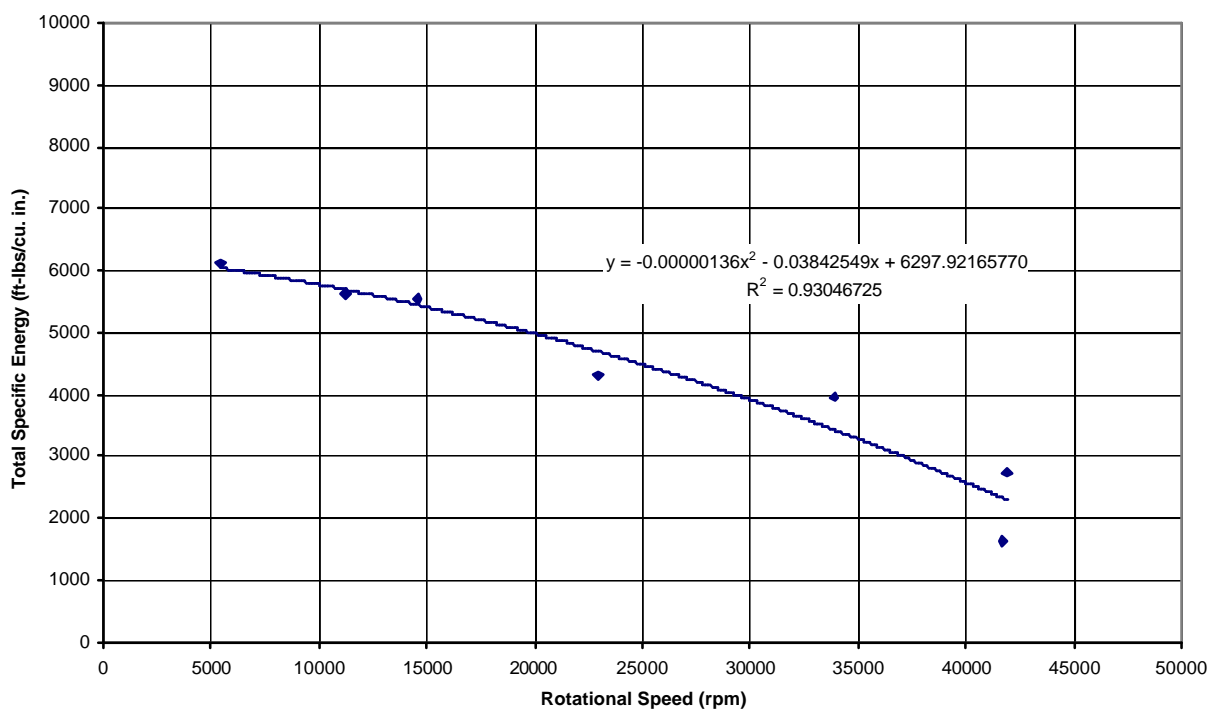


Early Check Out Test Results using Mars Worn Light Set Bit with Berea Sandstone at $3 \mathrm{Kgm}$ WOB and Nitrogen Flow

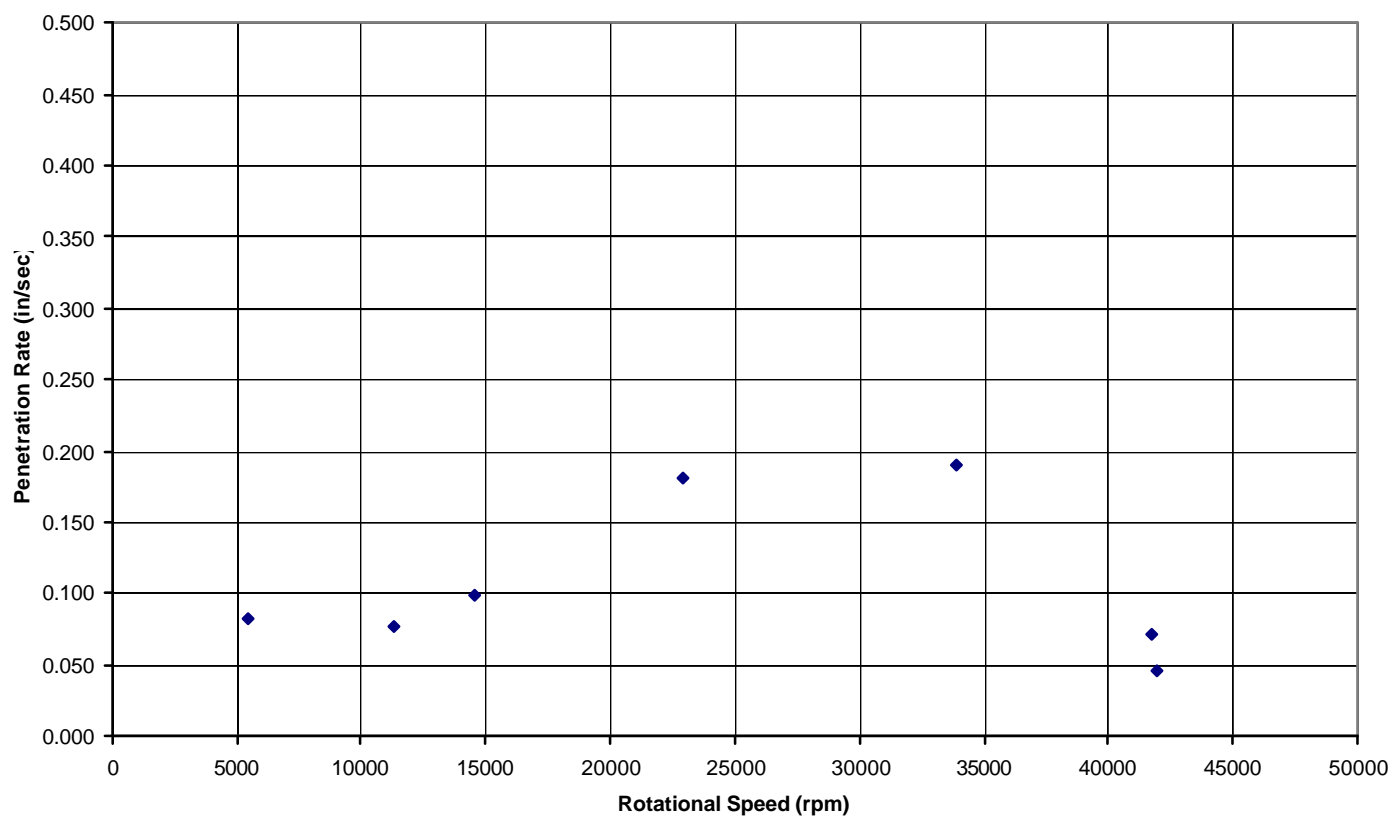

Preliminary Test Results using New Heavy Set Bits \#1 and \#4 with Berea Sandstone at $3 \mathrm{Kgm}$ WOB and Nitrogen Flow

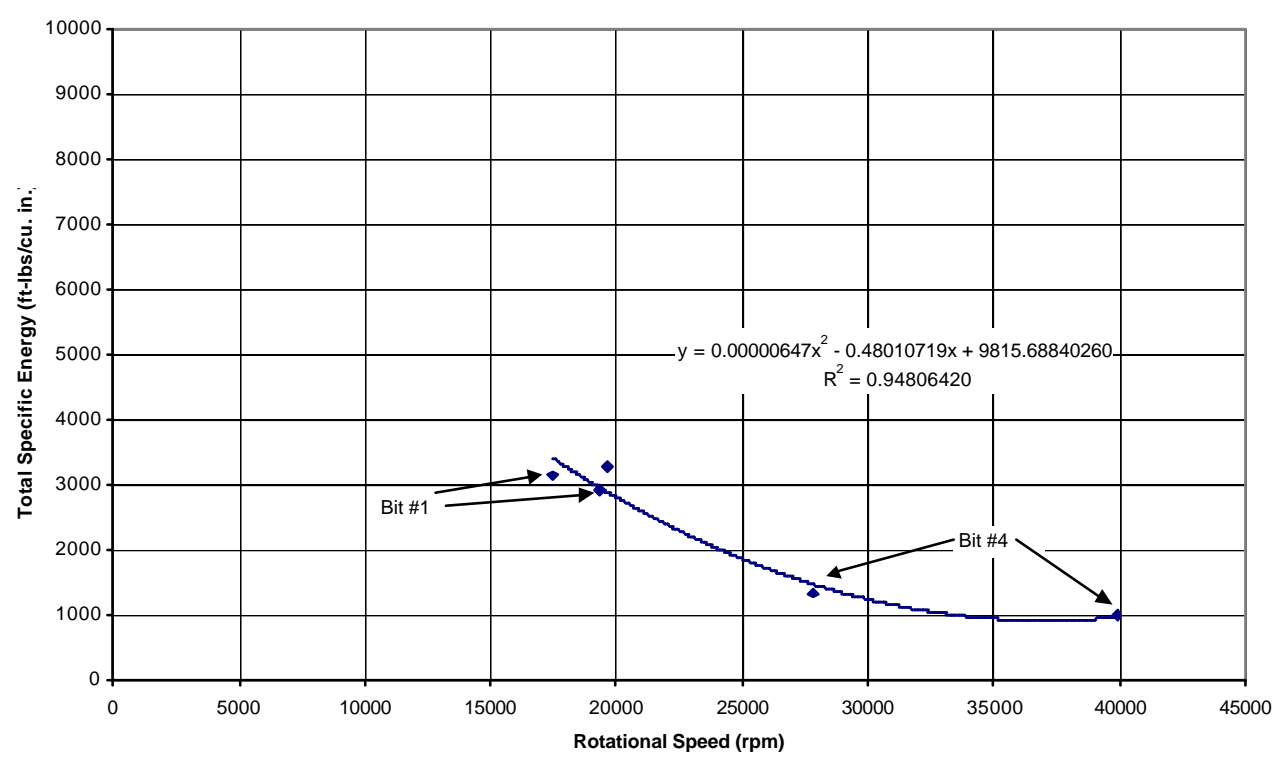


Preliminary Test Results using New Heavy Set Bits \#1 and \#4 with Berea Sandstone at $3 \mathrm{Kgm}$ WOB and Nitrogen Flow

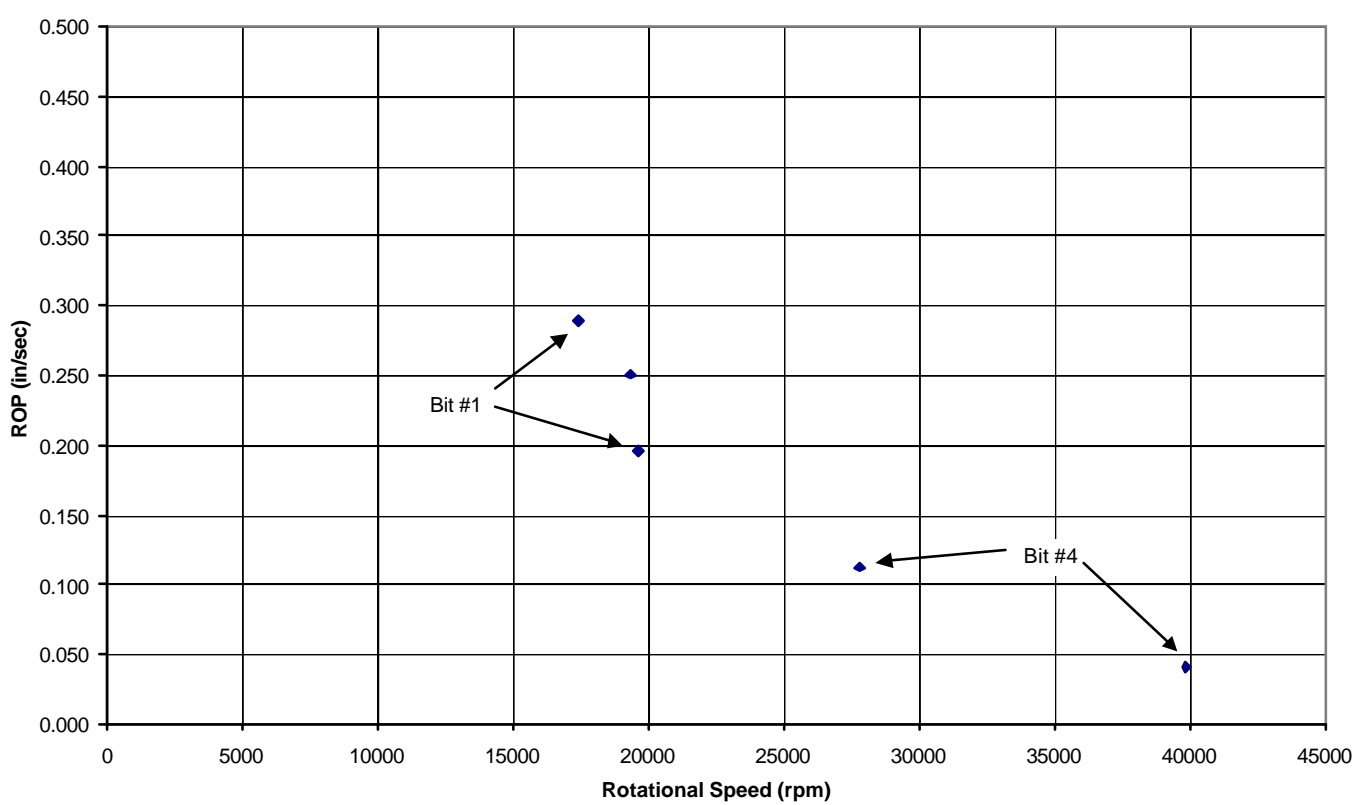

DOE HS Gas Pressure Effect on Load

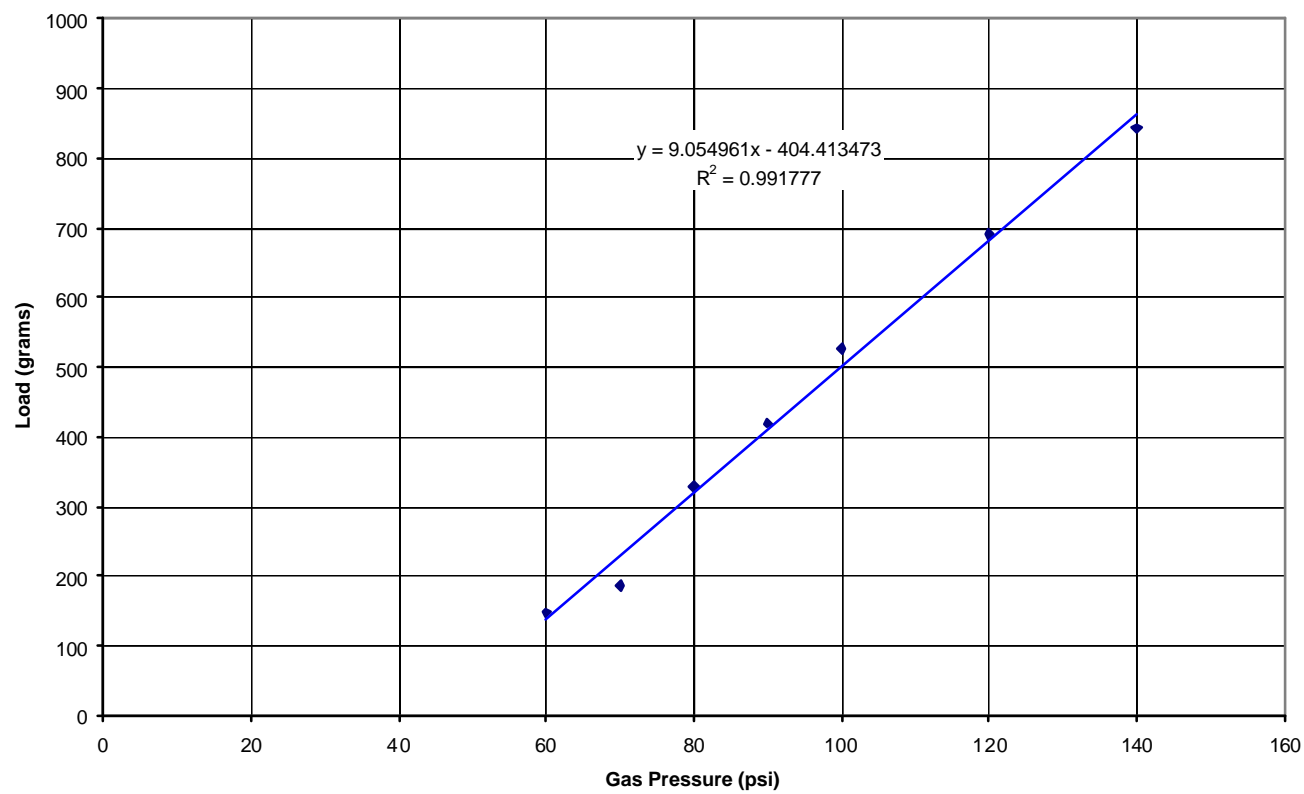




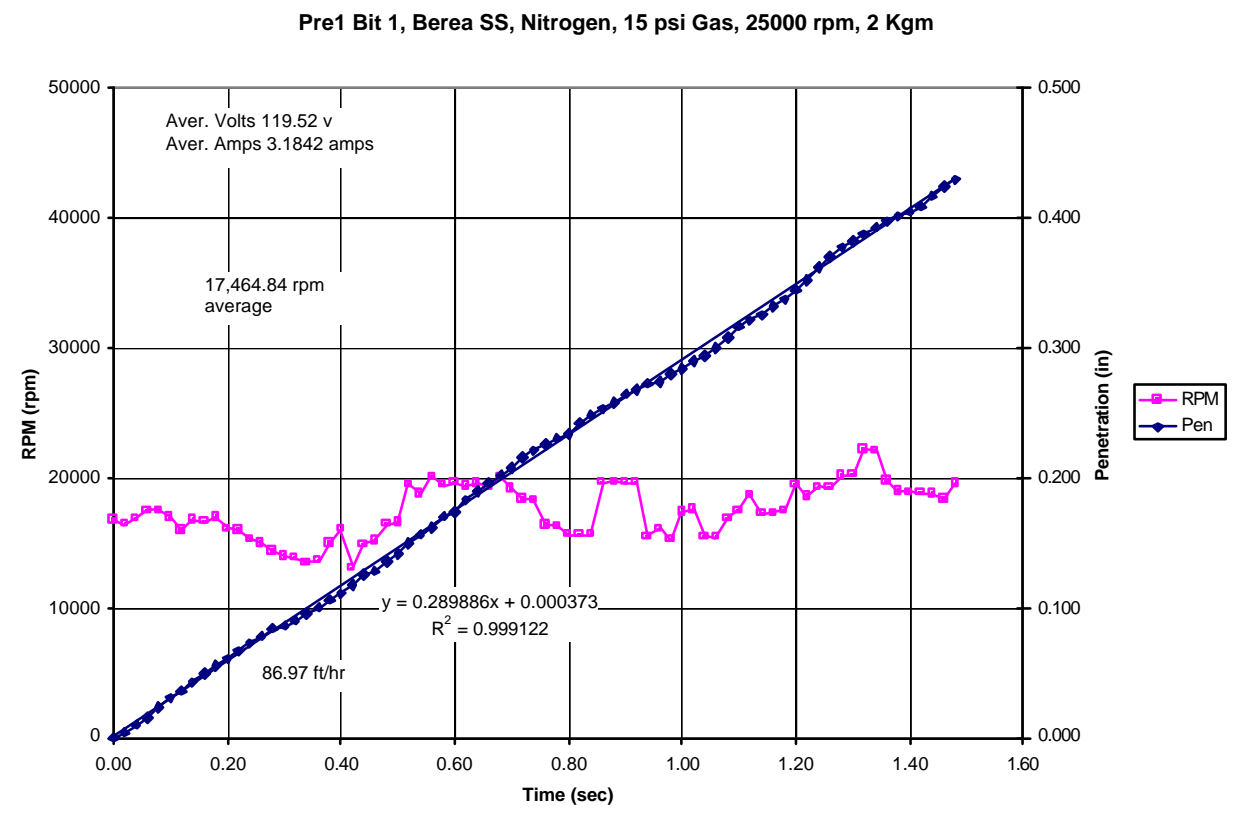

Pre2 Bit 1, Berea SS, Nitrogen, 50 psi Gas, 25000 rp,, 2 Kgm WOB

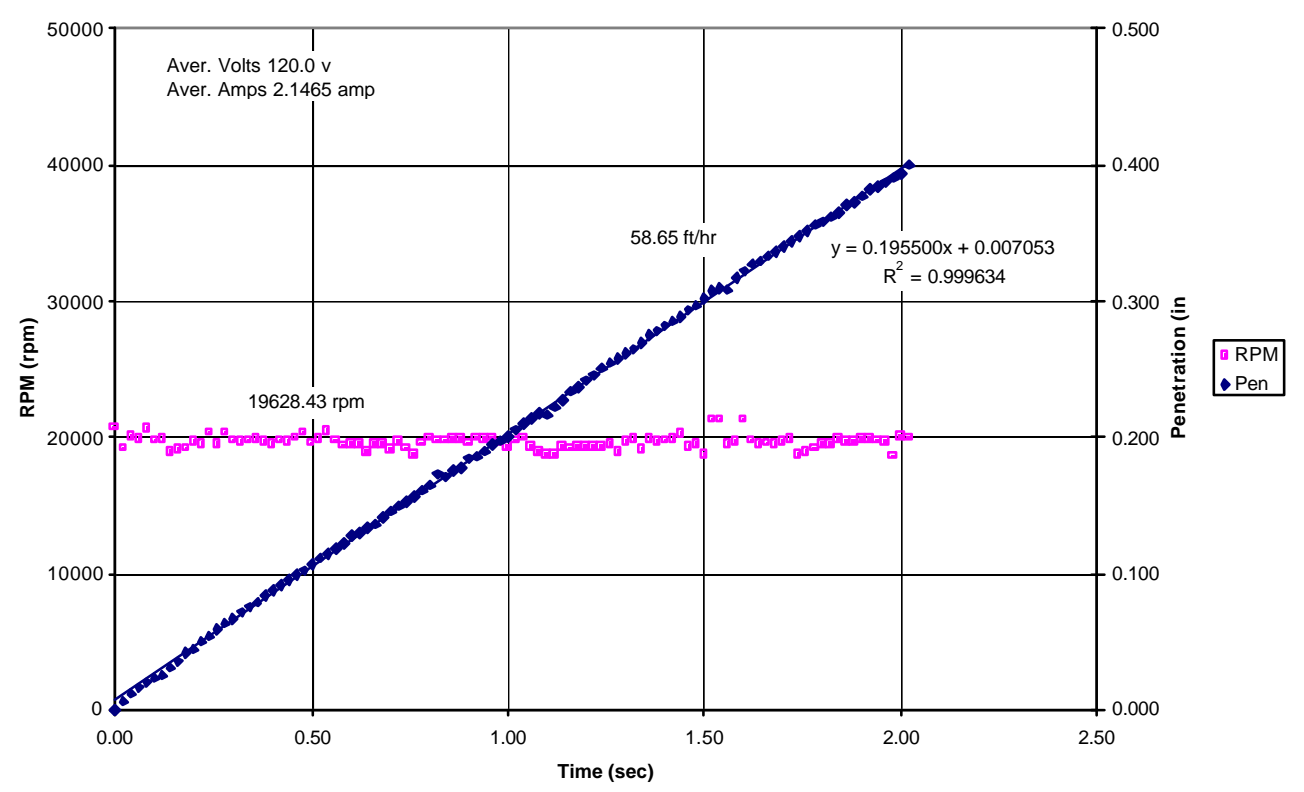


Pre3 Bit 1, Berea SS, Nitrogen, 100 psi Gas, 25000 rpm, 3 Kgm

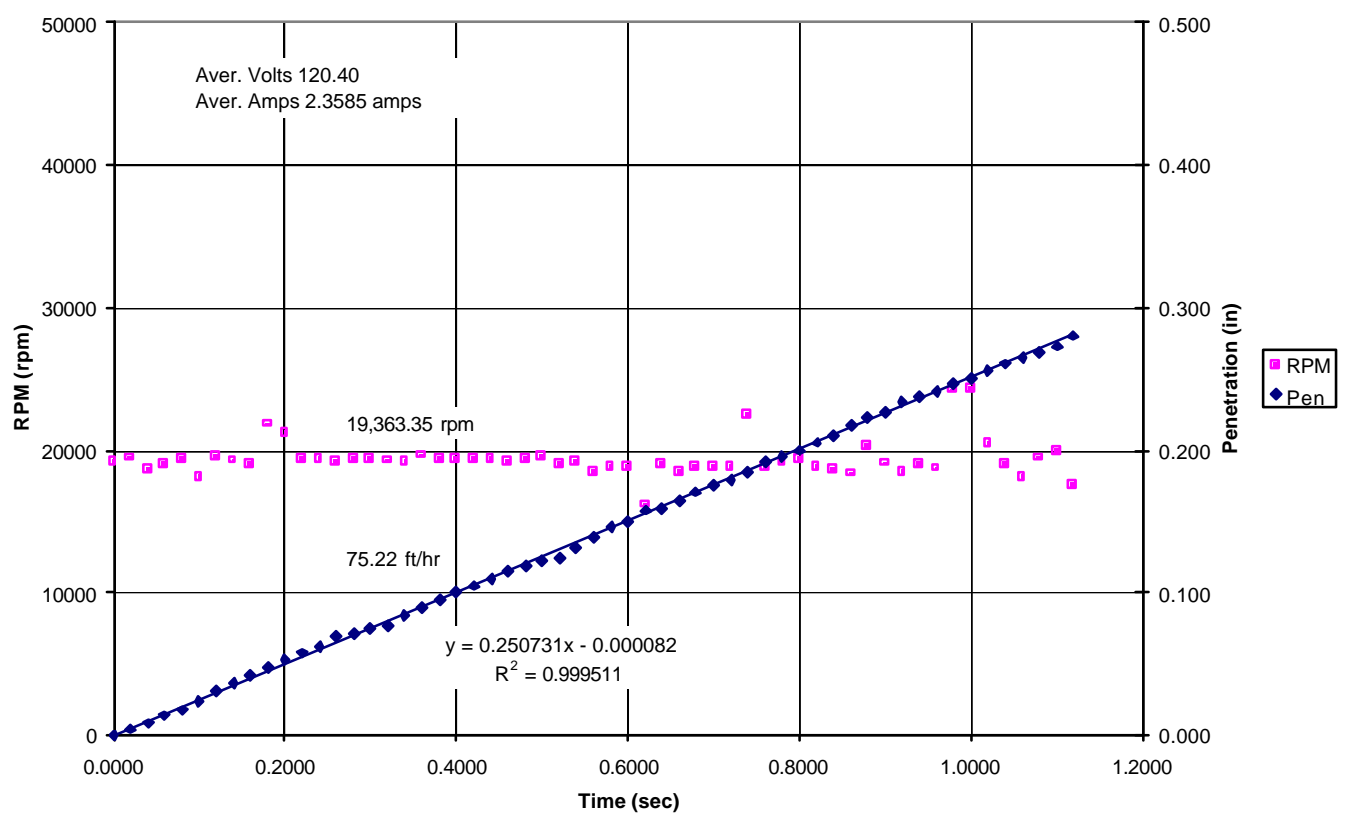

Pre4 Berea ss, , Nitrogen, 100 psi Gas, 30,000 rpm, 3 Kgm WOB

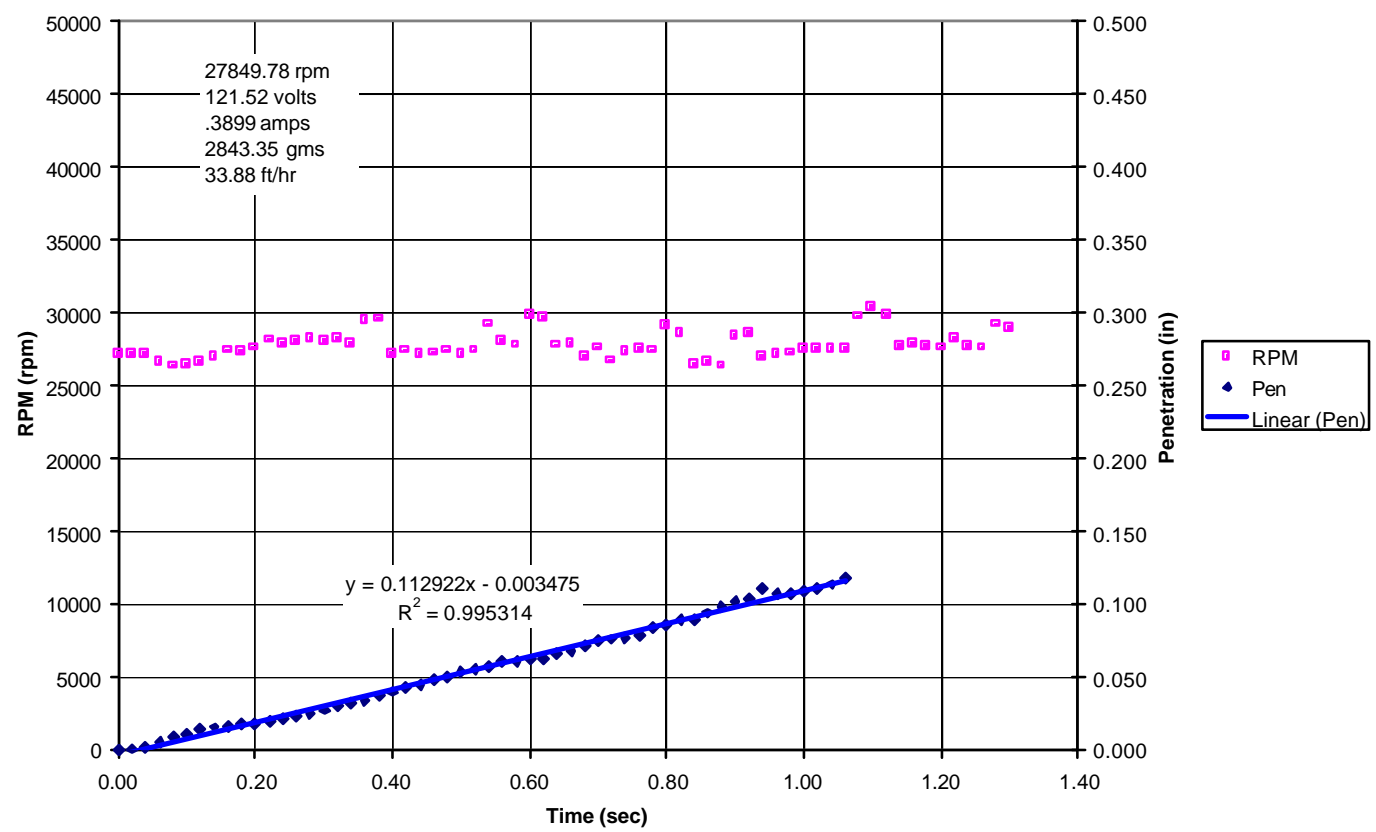


Pre5 Berea SS, Nitrogen, 100 psi Gas, 40,000 rpm, 3 Kgm WOB

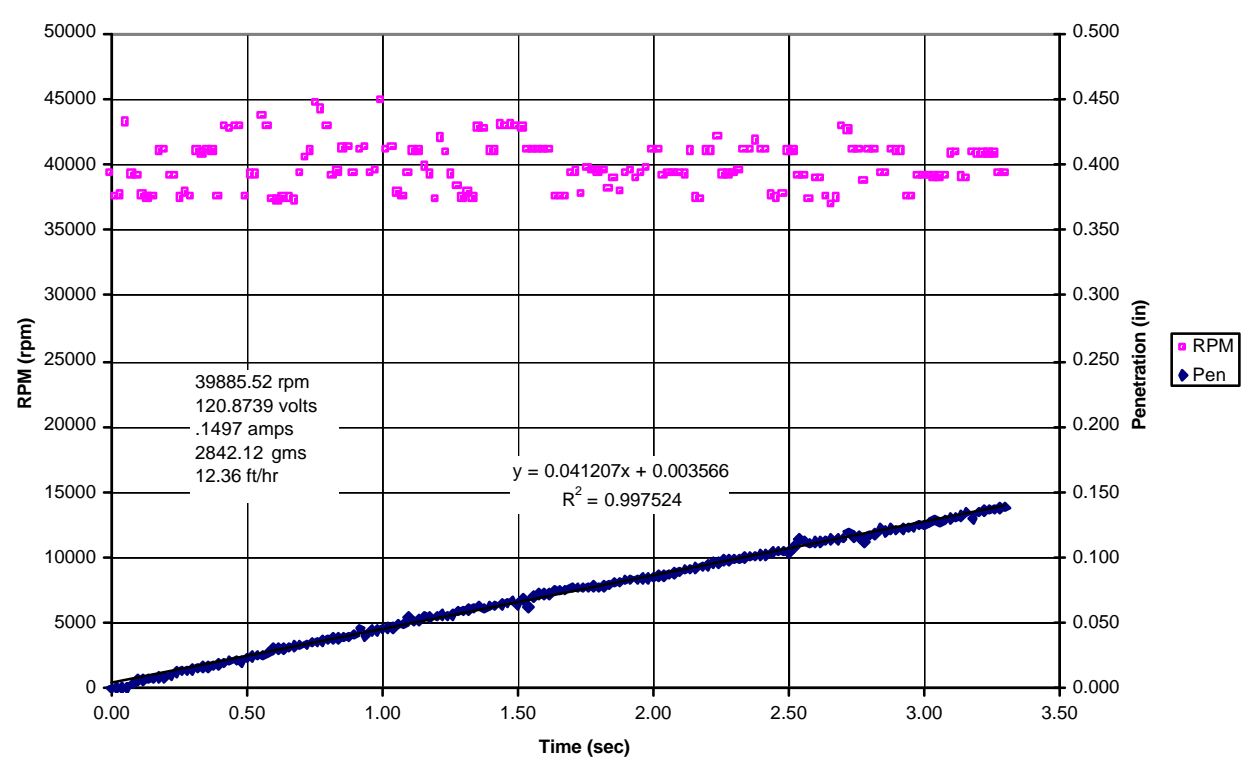

Pre6 Berea SS, Nitrogen, 100 psi Gas, 50,000 rpm, 3 Kgm WOB

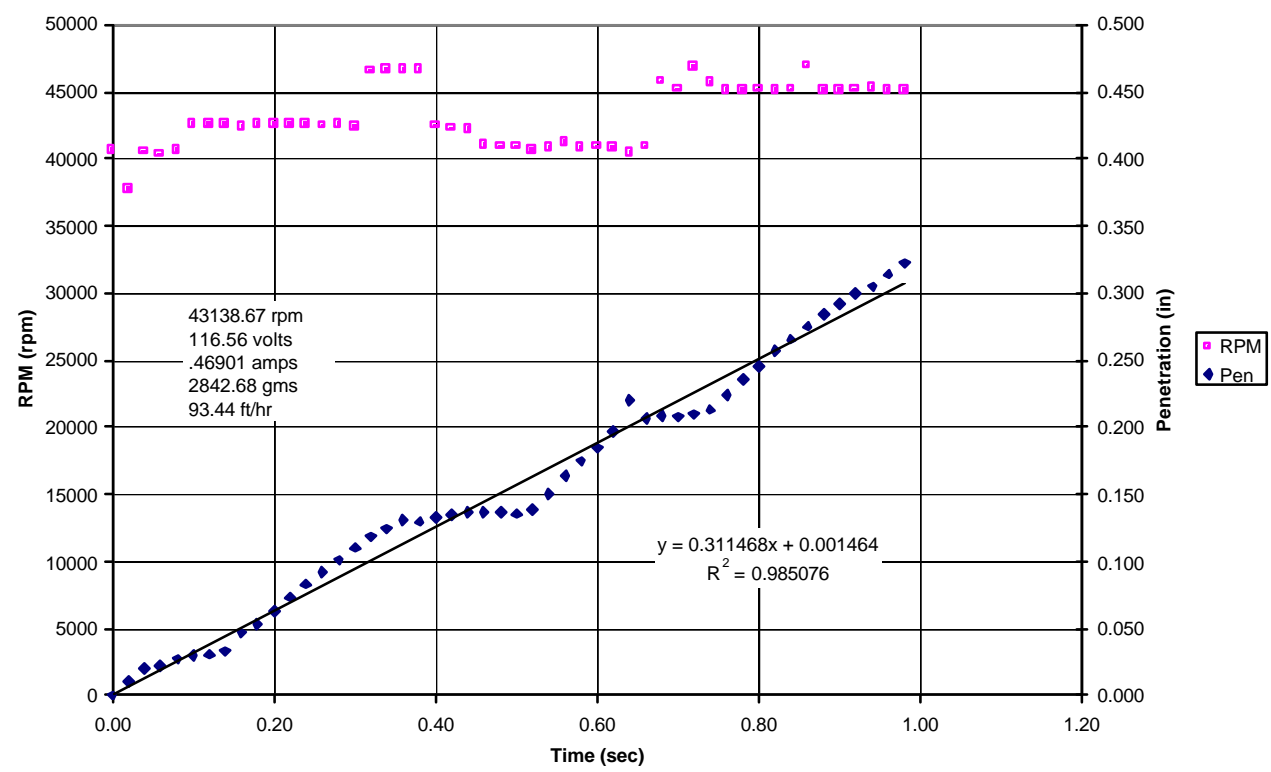




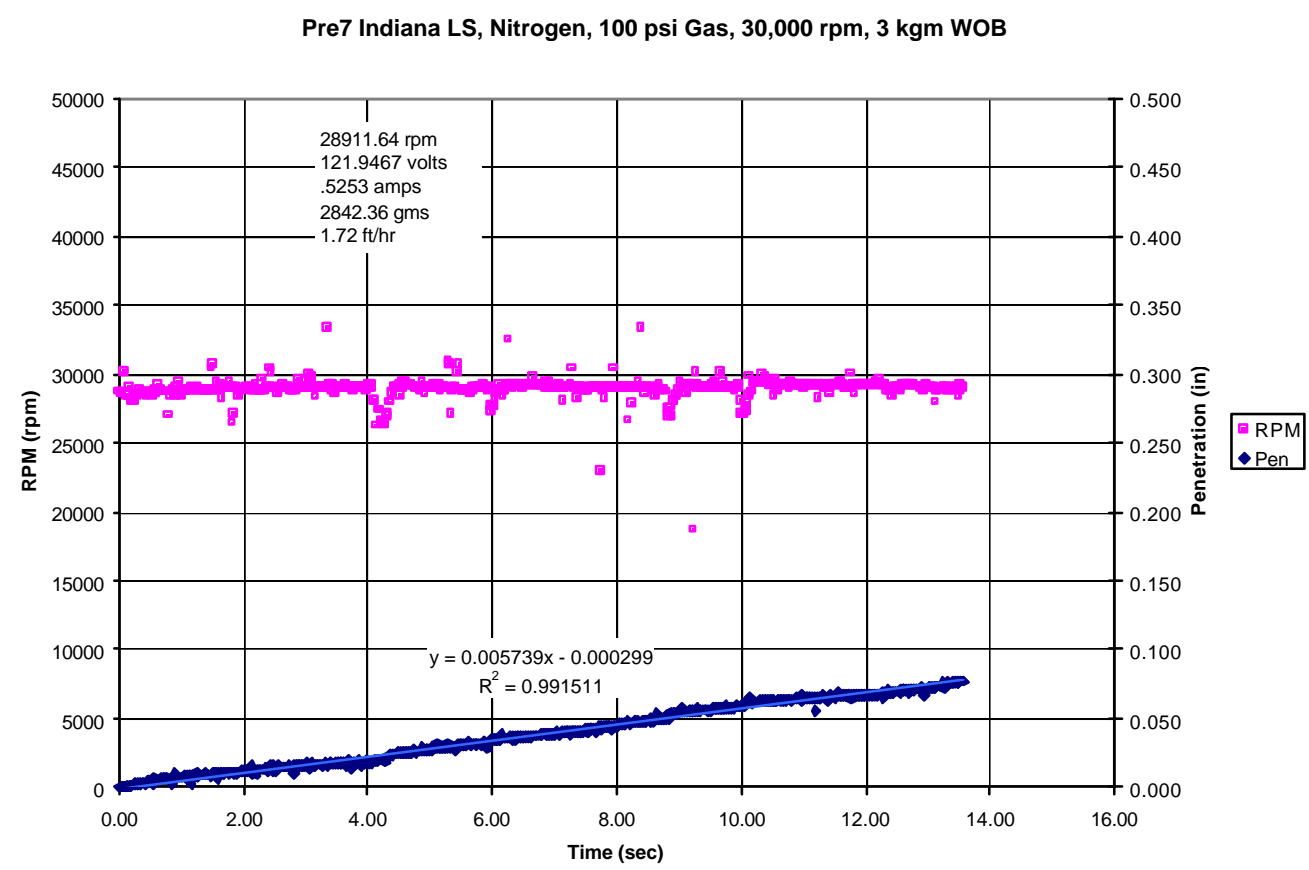

Pre8 Indiana LS, Nitrogen, 100 psi Gas, 30,000 rpm, 3 kgm WOB

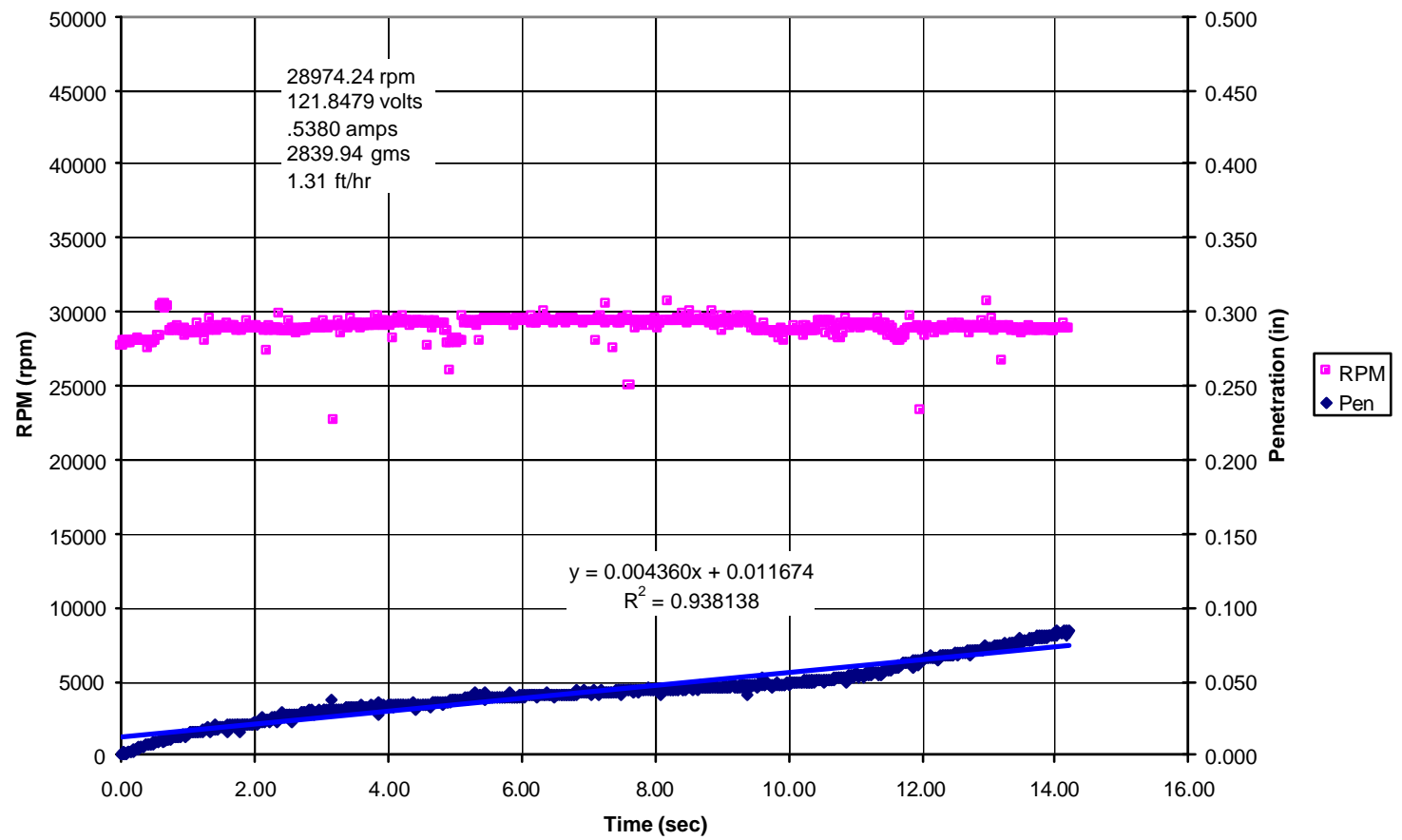


Bit \#1
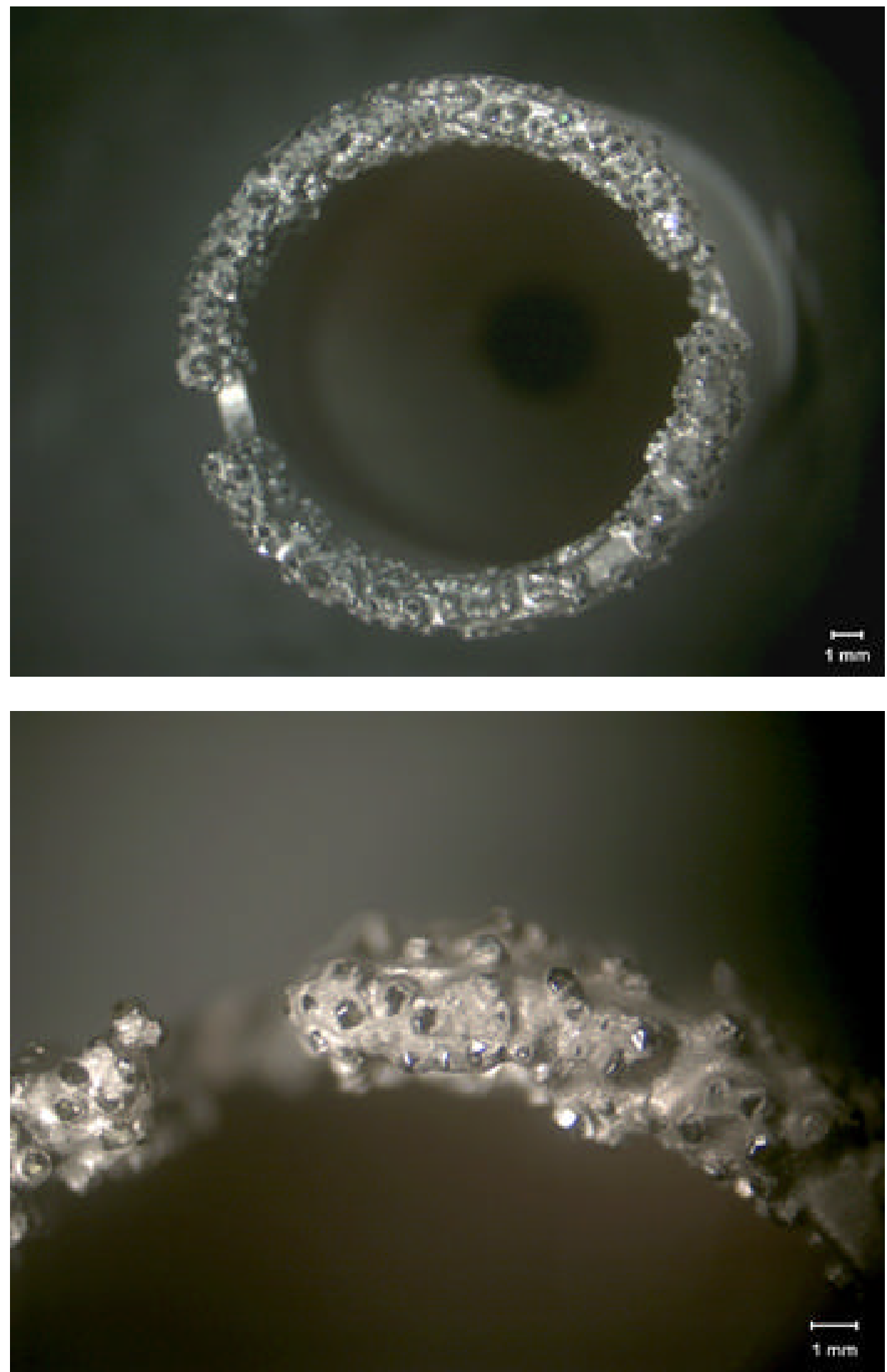
Bit \#2
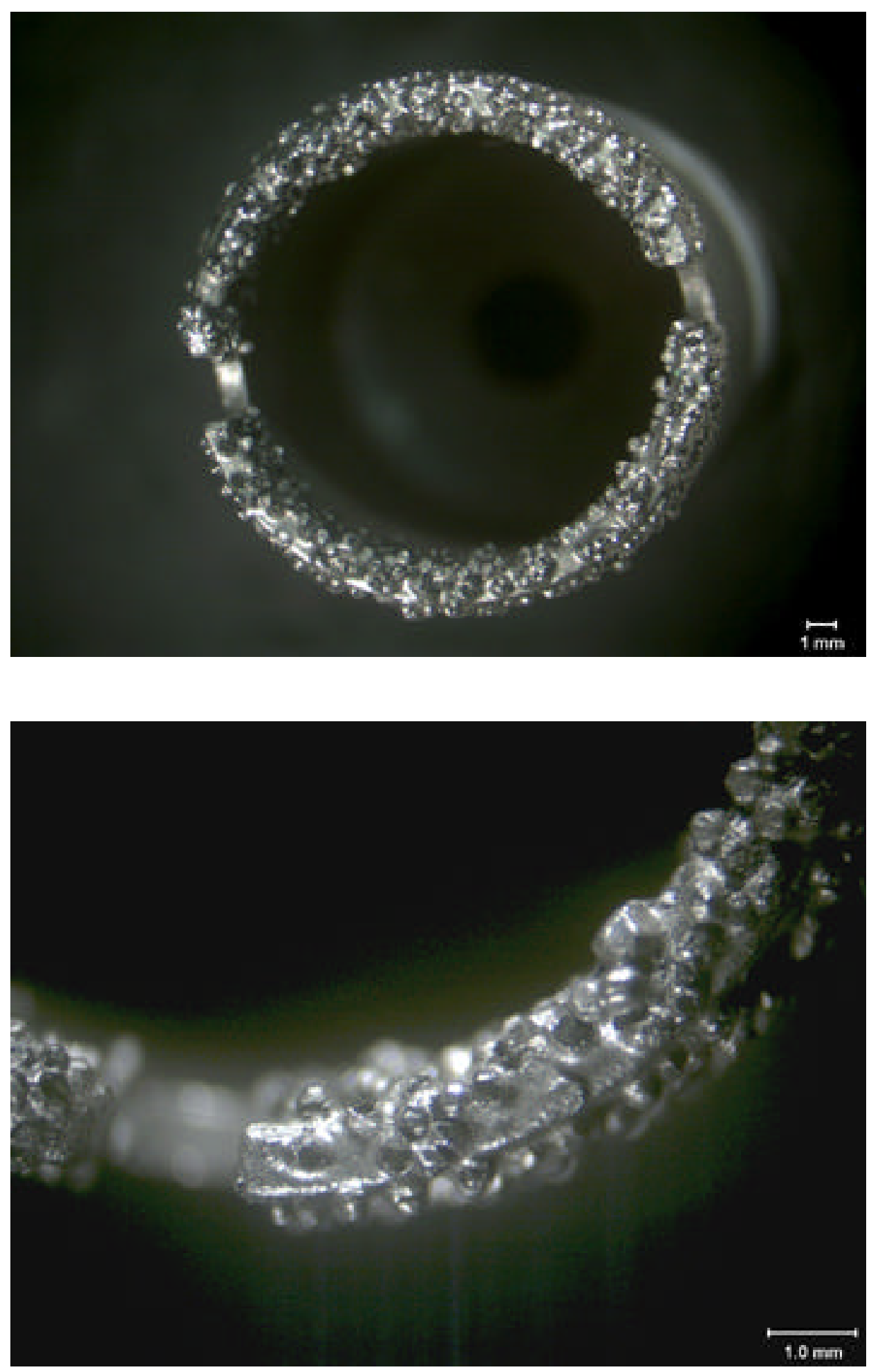


\section{Bit \#3}
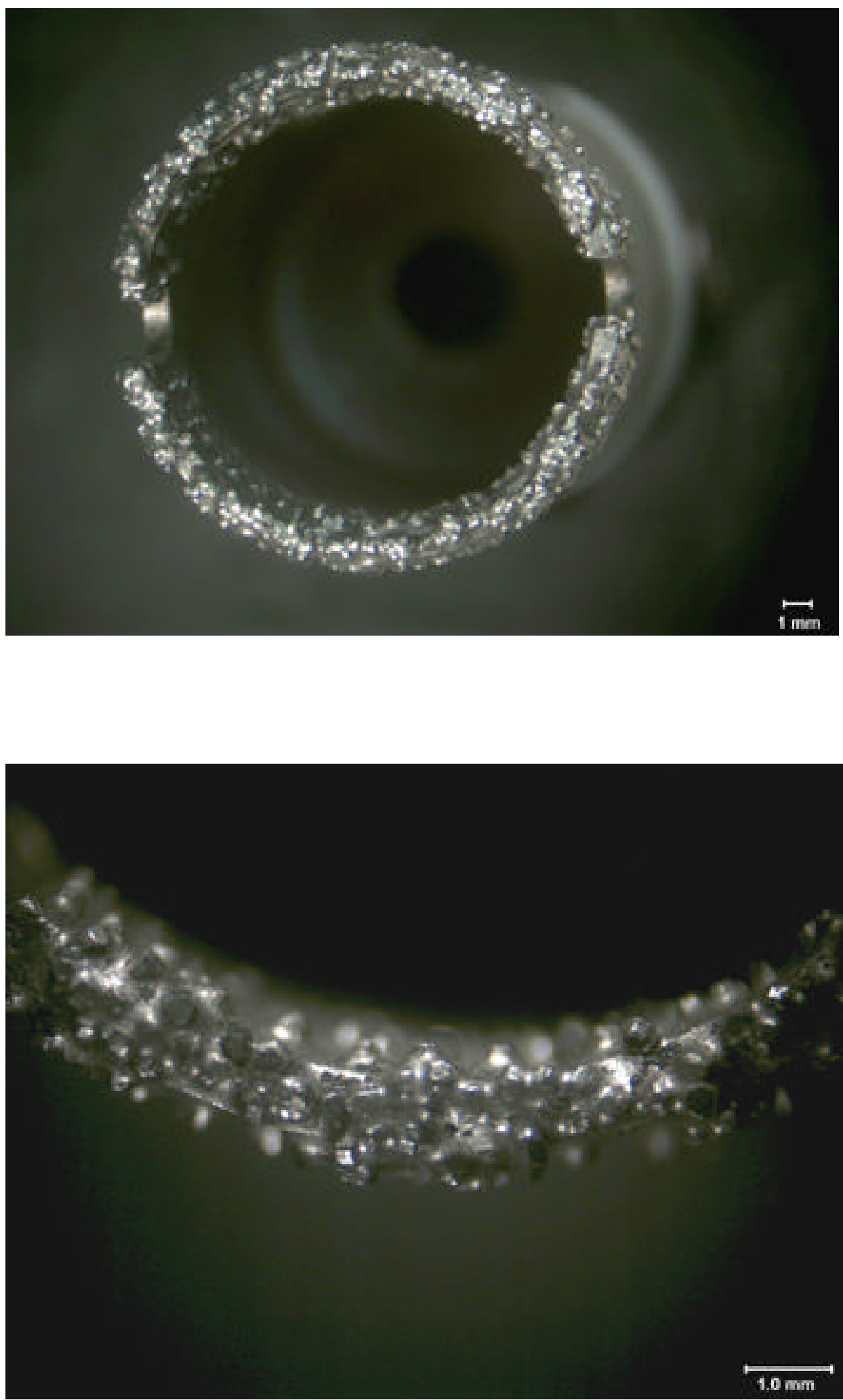
Bit \#4
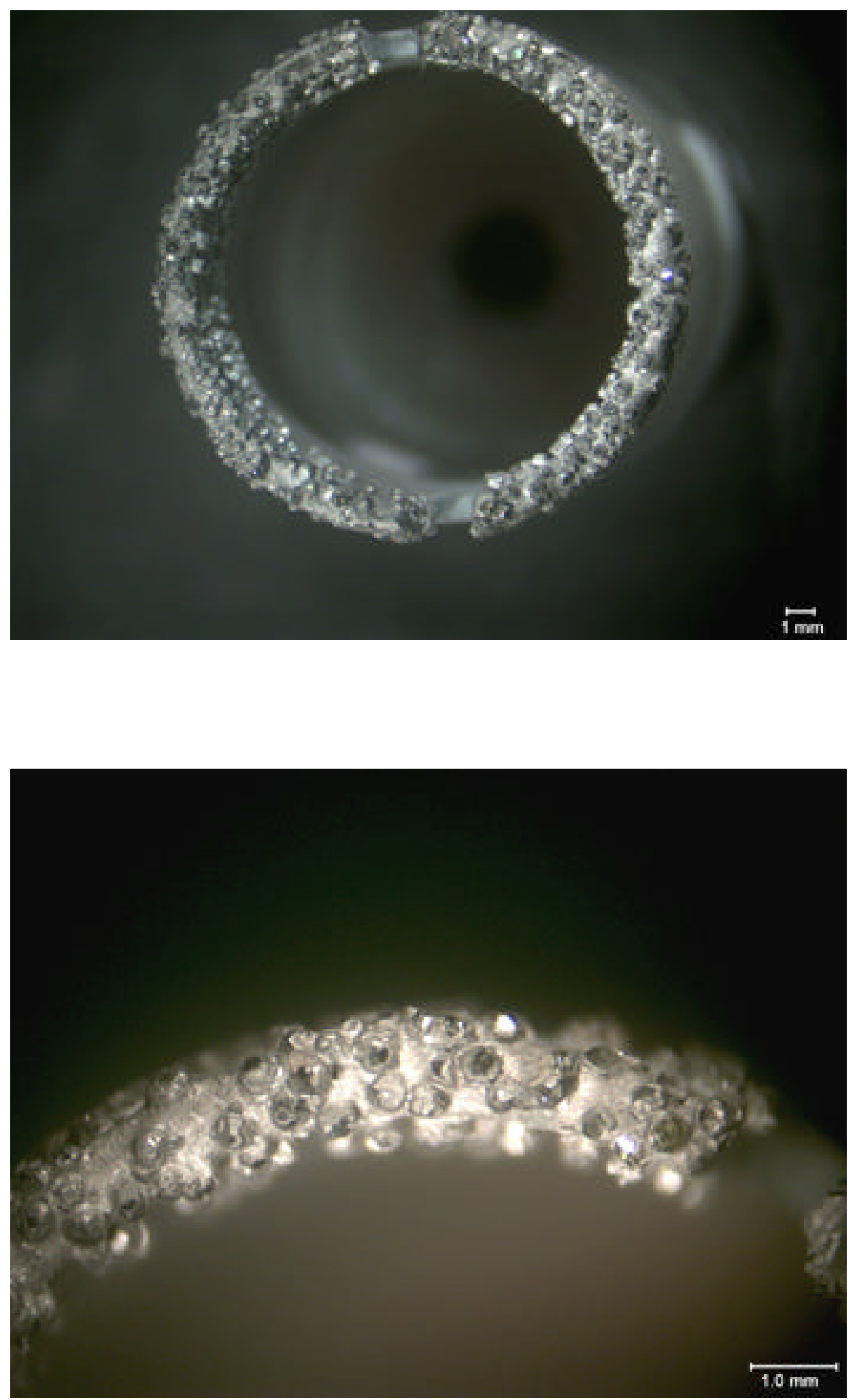
Bit \#5
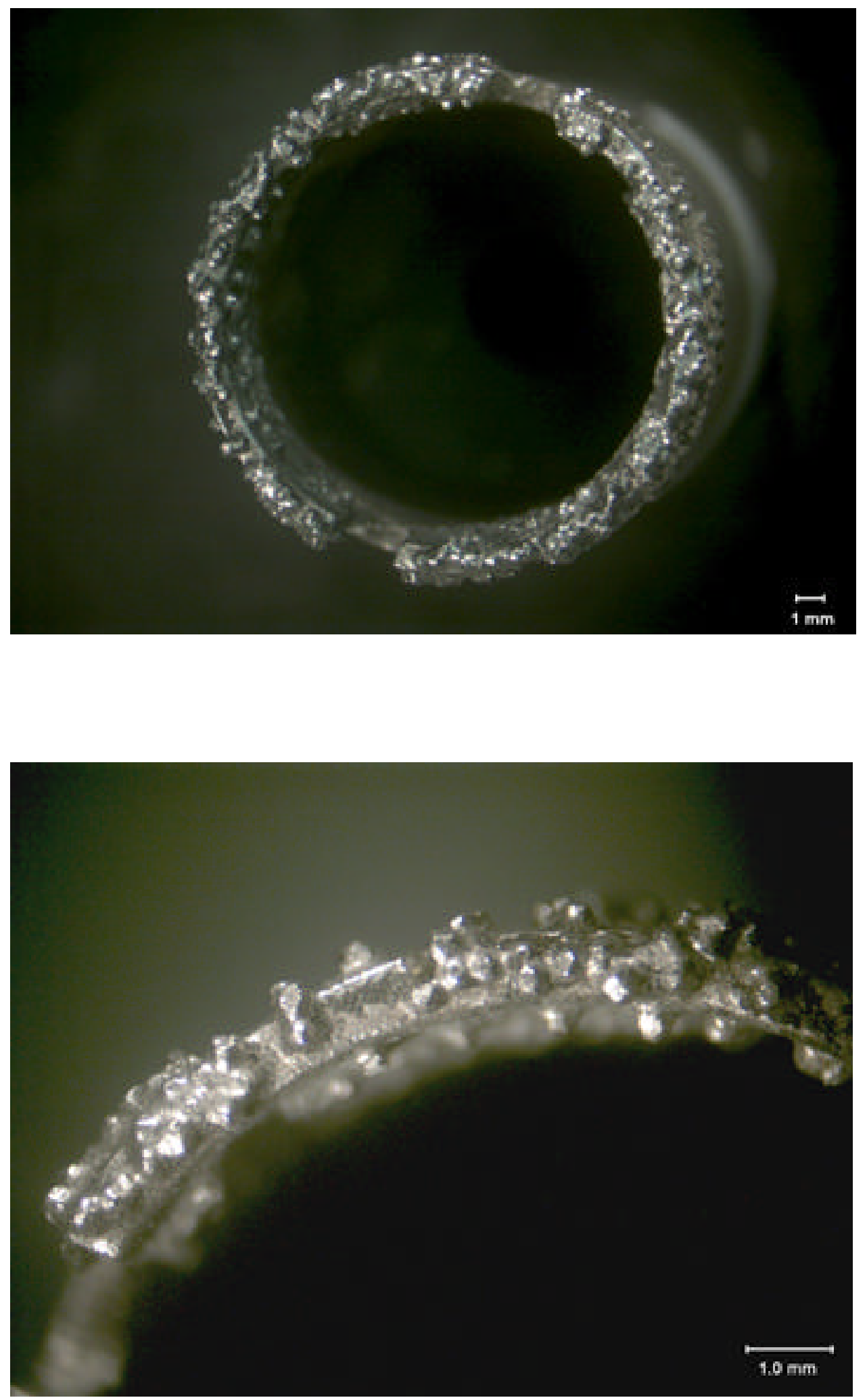


\section{RESULTS AND DISCUSSION}

August 26, 2003

Kick-off meeting in Tulsa (Power Point presentations)

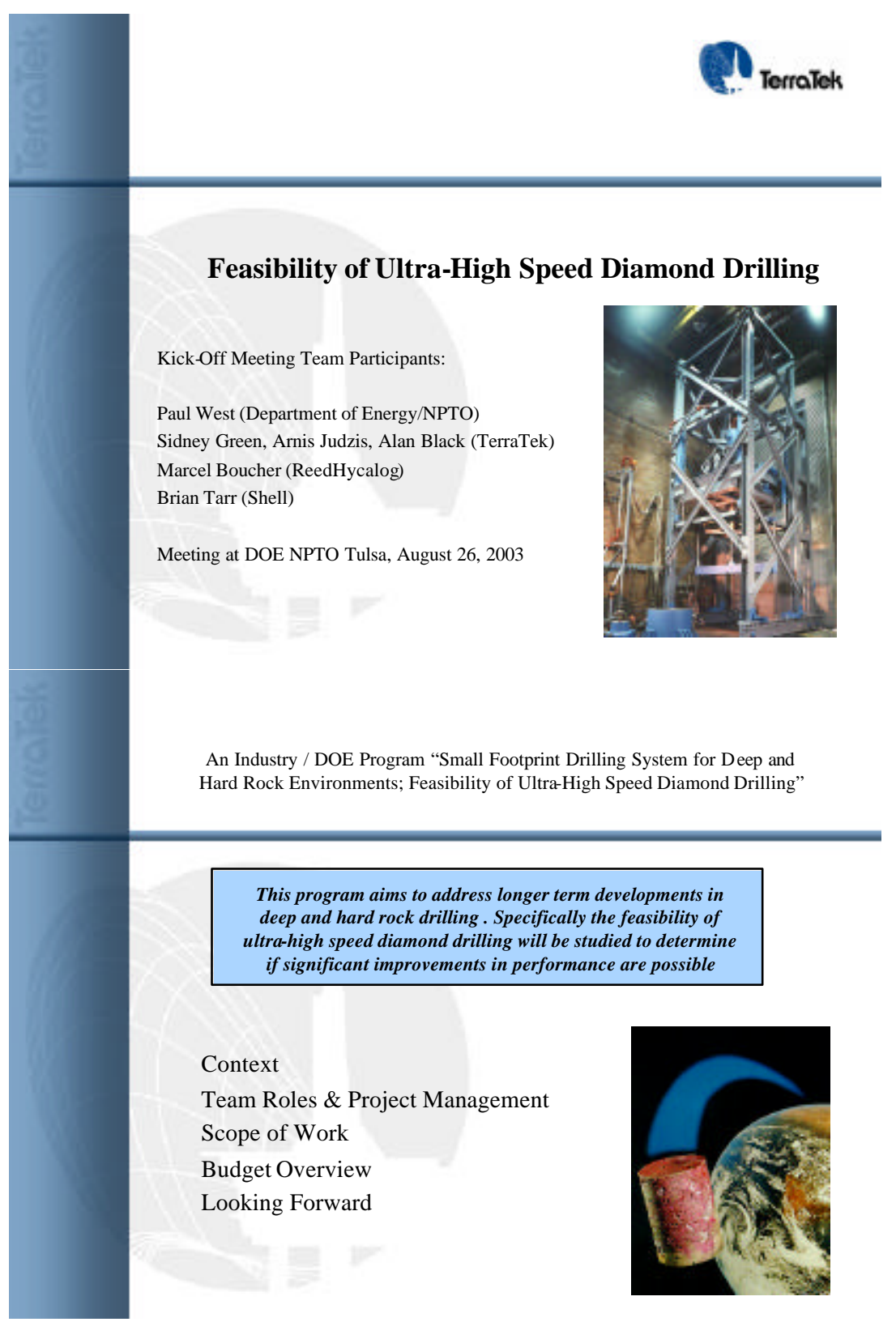




\section{Context}

- Economic Benefit

Domestic developments in drilling tools and testing

Potential for increased activities in oil and gas plays

- Drilling Performance

Diamond product bit applications for increased rate of penetration

Directional drilling applications

Potential for both slim and larger hole sizes

- Target Markets

Gas, deep gas plays

Domestic oil, where drilling performance can be improved

-Advantages in feasibility study on small scale, followed by slim sizes -

Economics (start-up with high day rates difficult with prototype tools)

Ability to study rate of penetration and specific energy effects

Bench scale test rig offers easy access to results

Drilling conditions are carefully controlled $\&$ measured (data acquisition)

Equipment can be modified and experiments replicated

Provides wide range of experiments - fluids, rock types, rotary speed, etc.

Team Roles and Project Management

\section{Scope of Work}

Applications and prior art for ultra -high -

Assess drilling applications requiring improvement

Access information from available sources

- Concept development -

Engineer and evaluate concept with bench scale testing*

Review progress against plan

- Demonstration of concept -

Benchmark performance with sizes up to 3" range

Prepare final report on 'Feasibility of Ultra-High Speed Diamond Drilling'

*Note that an important aspect of this program will be to evaluate the significance of different phenomenon associated with ultra-high speed diamond drilling - What is the relationship of specific energy with face velocity? We need to do experiments which $w$ with less energy. Perhaps some examination of cuttings, etc. will become necessary. 


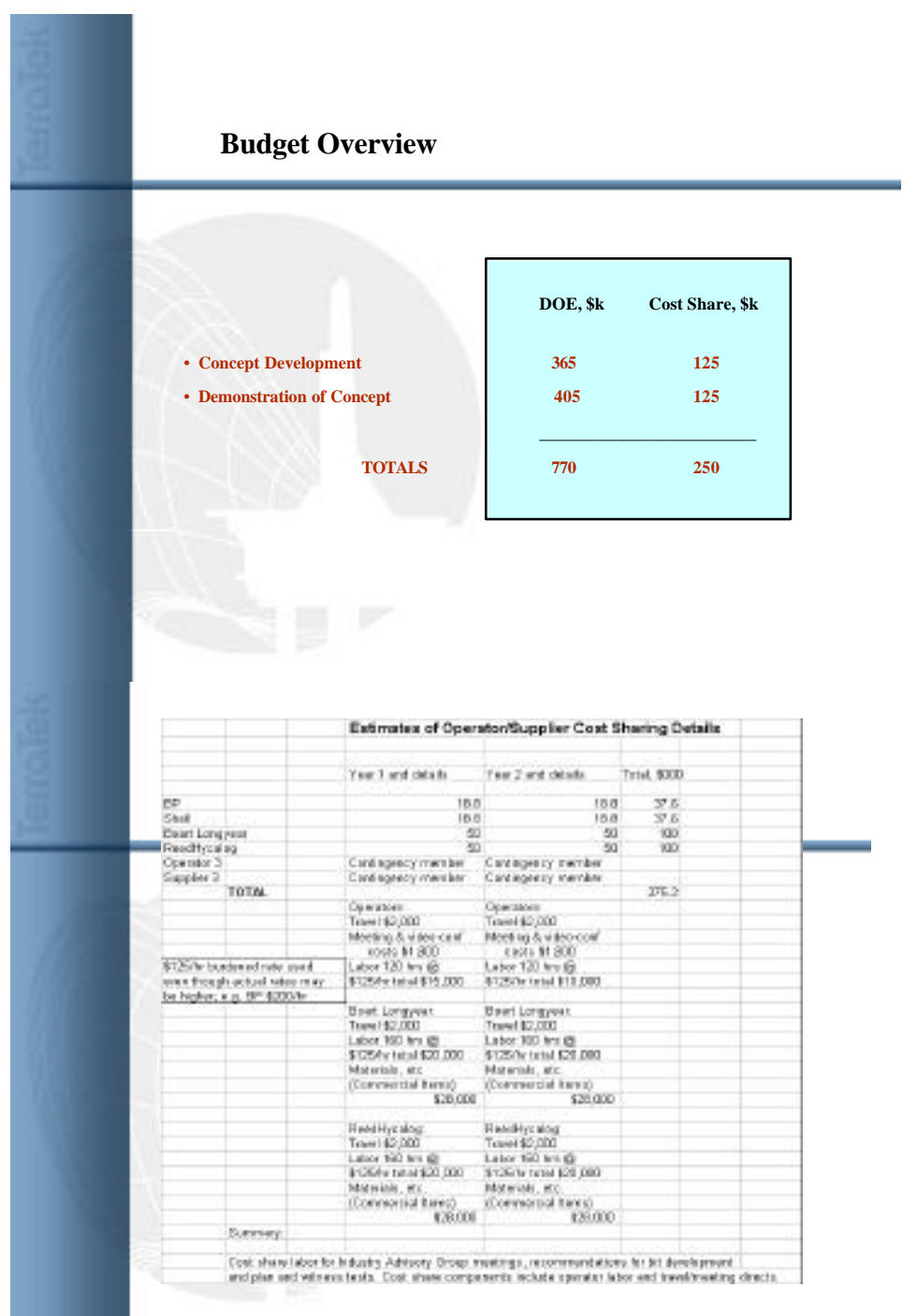

\section{Looking Forward}

- TerraTek plans to convene team in Houston (probably $4 \mathrm{Q} 2003$ ) to finalize test

conditions and review bit and equipment developments

- Upgrades to bench scale facility will be necessary end 2003.

Closure

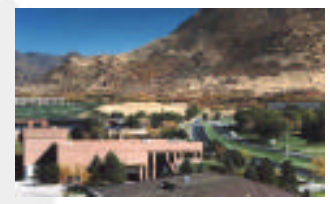

Questions and Answers

TerraTek
400 Wakara Way
Salt Lake City. UT 84103

Alan Black (801) 5842441, FAX x2406, ablack@eterratek.con 


\section{Test Program and Challenges}

Budget Period 1- Small Bench Testing to Determine High Speed Drilling Phenomenon

Budget Period 2- Slim-hole Testing to Determine High Speed Drilling Performance

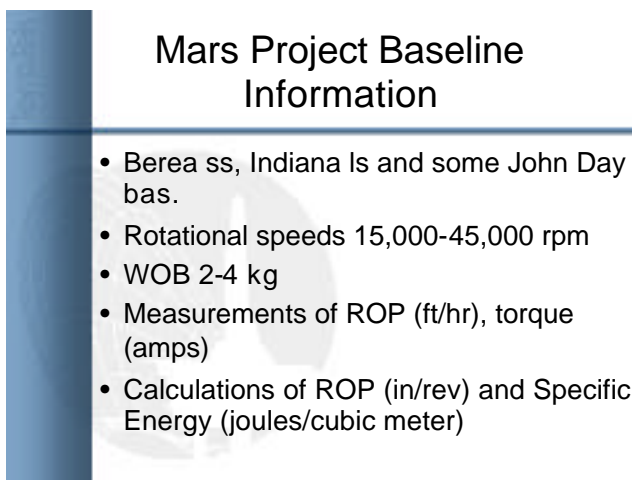

\section{Budget Period 1 Objectives}

- Access deep/hard drilling applications

- Design and engineer bits/equipment/matrix

- Determination of high speed/specific energy phenomenon

- Small bench scale drilling/coring testing

- Analysis of bench scale results and concept

- Engineering design of scaled up bits

- Transfer technology/lessons learned

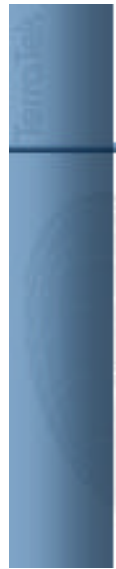

\section{Test Equipment}

$\begin{array}{cc}\text { - Budget Period 1 } & \text { Budget Period 2 } \\ \text { - Use basic bench set } & - \text { Large high speed motor } \\ \text { up with Korford 0- } & \text { TBD with } 200 \text { to } 500 \mathrm{lb} \\ 51,000 \mathrm{rpm} \text { hall effect } & \text { ft stall torque at 12,000 } \\ \text { motor } & \text { rpm maximum } \\ -788 \mathrm{oz} \text { in }(49.3 \mathrm{lb} \text { in } & - \text { High speed swivel } \\ \text { or 4.1 lb ft) stall } & - \text { Thrust bearing } \\ \text { torque } & - \text { Shaft and rotary seals } \\ \text { - set up for nitrogen } & - \text { Fluid collection can } \\ \text { injection } & - \text { Bit/shaft stabilizer } \\ \text { - need modification for } & - \text { Mounting to existing } \\ \text { pumping liquids } & \text { drill rig }\end{array}$

\section{Budget Period 2 Objectives}

- Job pre-planning advisory meeting

- Prototype bit design and test equipment fabrication

- Determination of drilling performance

- Slim-hole scale drilling/coring testing

- Analysis of results and benchmarking results

- Technology transfer-advisors review, recommendations and publications

- Final report to DOE

\section{Drilling and Coring Bits}

$\begin{array}{lc}\text { - Budget Period 1 } & \text { - Budget Period } 2 \\ -0.75 \text { OD x 0.6 ID core } & - \text { Up to 3" diameter range } \\ \text { bits } & \text { drill bits (full face) } \\ - \text { Possibly } 0.75-1 " & - \text { Up to to 3" OD x } 2.5 \text { " ID } \\ \text { diameter drill bits (full } & \text { range core bits }(30 \% \text { of } \\ \text { face) } & \text { full face) } \\ -0.75 " \text { drilling stroke } & -6-12 \text { " drilling stroke } \\ - \text { Balanced at 50,000 } & - \text { Balanced at 12,000 rpm } \\ \text { rpm } & - \text { Bits including natural } \\ - \text { Bits including natural } & \text { diamond, impregnated, } \\ \text { diamond, } & \text { TSP \& PDC } \\ \text { impregnated or TSP } & \end{array}$



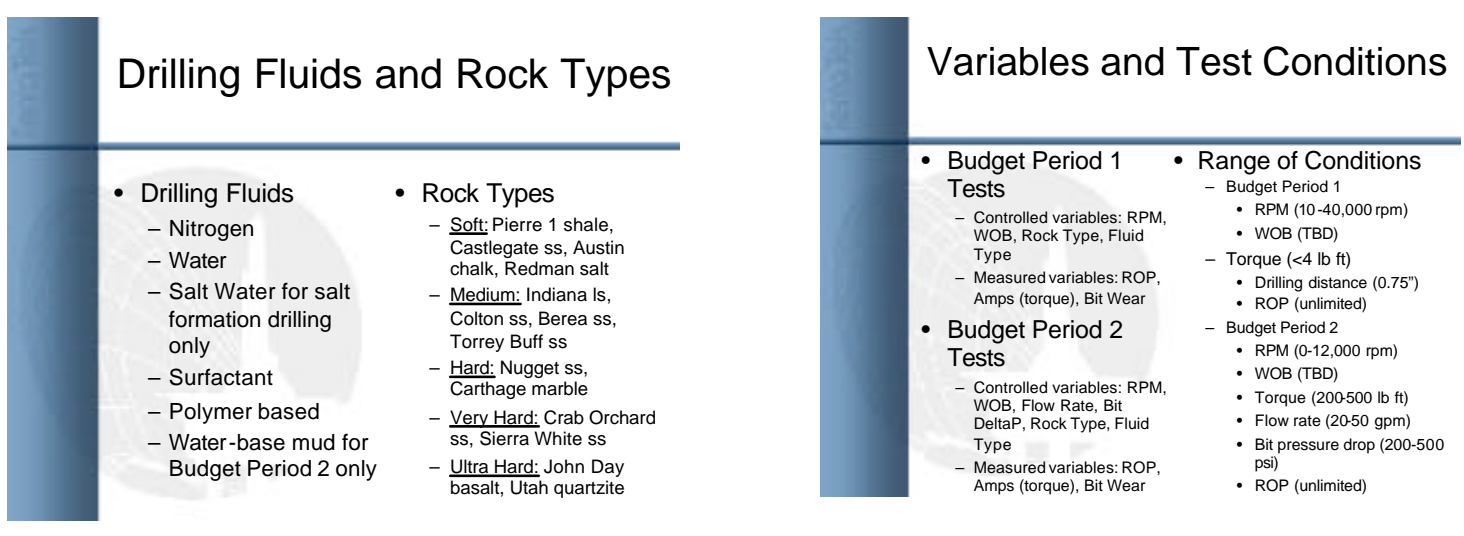

\begin{tabular}{|c|c|}
\hline \multicolumn{2}{|c|}{$\begin{array}{l}\text { Phenomena Determination } \\
\text { with Bench-scale Testing }\end{array}$} \\
\hline $\begin{array}{l}\text { Define and } \\
\text { understand } \\
\text { phenomena: } \\
\text { - Specific energy vs. } \\
\text { RPM } \\
\text { - How cutting occurs } \\
\text { for different rocks } \\
\text { - How different } \\
\text { diamonds behave } \\
\text { and will PDC cut at } \\
\text { high RPM }\end{array}$ & $\begin{array}{l}\text { - What is the effect of } \\
\text { WOB and cuttings } \\
\text { removal } \\
\text { - What are drilling fluid } \\
\text { and pore fluid effects } \\
\text { - How can technology } \\
\text { be transferred to full } \\
\text { face bits? }\end{array}$ \\
\hline
\end{tabular}

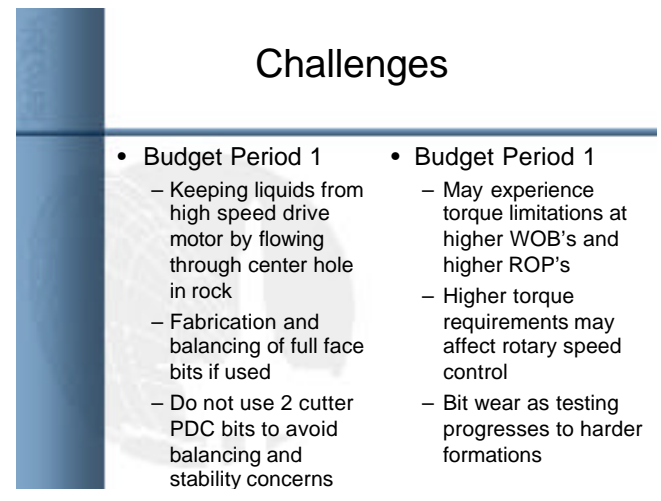

\section{CONCLUSIONS}

- TerraTek has reviewed applicable literature and documentation and has convened a project kick-off meeting with Industry Advisors in attendance.

- TerraTek has designed and planned Phase I bench scale experiments. Some difficulties in obtaining ultra-high speed motors for this feasibility work were encountered though they were sourced mid 2004.

- TerraTek is progressing through Task 3 "Small-scale cutting performance tests". Some improvements over early NASA experiments have been identified. 